\title{
Die Berliner Debatte um die Neue Welt oder das europäische Wissen über das Globale
}

Doch noch sind wir nicht zu dem gelangt, was Alexander von Humboldt mit Blick auf den Übergang vom 18. zum 19. Jahrhundert - wie wir noch sehen werden - als eine „glückliche Revolution“ im Bereich eines empirisch fundierten Wissens bezeichnete. Auch auf diesem Gebiet tat Jean-Jacques Rousseau einen wichtigen Schritt, indem er auf die Defizite des europäischen Wissens seiner Zeit über die außereuropäische Welt aufmerksam machte. Denn in einer der wohl wichtigsten Anmerkungen zu seinem Discours sur l'origine et les fondements de l'inégalité parmi les hommes setzte sich der Genfer Philosoph im Jahre 1755 kritisch mit dem im Europa seiner Zeit erreichten Stand anthropologischer Kenntnisse auseinander. Er hatte die praktischen wie die epistemischen Grenzen dieses Wissens über die Welt, über das Globale erkannt.

Dabei hob er die unübersehbare, von den meisten der europäischen Philosophen aber sehr wohl übersehene Asymmetrie zwischen dem Wissensstand der aus den verschiedensten europäischen Ländern stammenden Reisenden einerseits und dem Reflexionsstand all jener Philosophen andererseits hervor, die ihre generalisierenden Überlegungen und Theorien zur Diversität des Menschengeschlechts nicht zuletzt auf der Grundlage mehr oder oftmals auch minder ausgedehnter und aufmerksamer Lektüren von Reiseberichten anstellten und entwickelten. Rousseau machte auf das Auseinanderklaffen des Wissens der Reisenden und der Daheimgebliebenen aufmerksam und stellte sehr wohl in Frage, dass diejenigen, die in Europa das Wissen sammelten, aber selbst nicht reisten und andere Kontinente, andere Kulturen nicht aus eigener Erfahrung kannten, den Diskurs über die außereuropäische Welt beherrschten - eine Position, für die etwa sein ehemaliger Freund Denis Diderot stellvertretend stand.

Jean-Jacques Rousseau betonte in diesem Zusammenhang die unabdingbare Notwendigkeit, diese fundamentale Asymmetrie innerhalb der weltweiten Zirkulation des Wissens zu durchbrechen, die im Übrigen nicht zuletzt durch die mangelnde Vorbereitung der allermeisten Reisenden verschärft werde. Er forderte, das in Europa gesammelte Wissen sozusagen einem ,Faktencheck` zu unterziehen, wie wir das mittlerweile auf Neudeutsch ausdrücken. Es suchte also, dem in Europa akkreditierten Wissen eine stärker empirisch fundierte Grundlage zu geben.

Zugleich hielt er auch einen gewissen Mangel hinsichtlich der (wissenschaftlichen) Ausrichtung mancher „hommes éclairés“ fest, die sich dessen ungeachtet vielfältigen Gefahren ausgesetzt und lange, anstrengende Reisen unternommen hätten, um bestimmte naturwissenschaftlich ausgerichtete Theo-

Ә Open Access. (C) 2021 Ottmar Ette, publiziert von De Gruyter. (c) BY-NC-ND Dieses Werk ist lizenziert unter einer Creative Commons Namensnennung - Nicht-kommerziell - Keine Bearbeitung 4.0 International Lizenz. https://doi.org/10.1515/9783110703467-013 
rien zu überprüfen. Dabei kam er auch auf jene beiden Expeditionen zu sprechen, die wir in unserer Auseinandersetzung mit der ersten Hälfte des 18. Jahrhunderts bereits erwähnt beziehungsweise analysiert haben:

Die Mitglieder der Akademie, welche die nördlichen Teile Europas und die südlichen Teile Amerikas durchlaufen haben, hatten sich mehr zum Ziele gesetzt, diese Gegenden als Geometer und weniger als Philosophen zu besuchen. Insofern sie jedoch das eine wie das andere waren, kann man die Regionen, welche von den La Condamine und den Maupertuis gesehen und beschrieben wurden, nicht als gänzlich unbekannt erachten. ${ }^{1}$

Rousseau hatte durchaus wahrgenommen, welche Expeditionen die „Académiciens" nach Lappland wie ins heutige Ecuador unternommen hatten, um die Thesen Newtons bezüglich der Abplattung der Pole und der Gestalt der Erde zu verifizieren oder zu falsifizieren. Man darf also sehr wohl annehmen, dass er die Berichte von Maupertuis und von La Condamine gelesen hatte. Der Verfasser des Discours sur l'inégalité, wie dieser Second Discours auch in abgekürzter Form oft benannt wird, ließ jedoch keinerlei Zweifel an seiner kritischen Einschätzung aufkommen: Nicht von den Geometern, sondern von den Philosophen erhoffte sich Rousseau die entscheidenden Verbesserungen des Kenntnisstandes über die außereuropäische Welt. Schon Rousseau ging es folglich um wesentlich mehr als um die Vermessung der Welt.

Räumte der Bürger von Genf auch gerne Gehalt und Qualität mancher Reiseberichte ein, die im 18. Jahrhundert veröffentlicht worden waren, so verbarg er doch seine fundamentale Kritik am allgemeinen Niveau anthropologischer beziehungsweise ethnologischer Kenntnisse nicht. Dabei nahm er bei aller Bewunderung für das Werk eines Buffon auch den Bereich der Naturgeschichte und insbesondere der von ihren Vertretern genutzten Quellen nicht von dieser Kritik aus. Rousseau beabsichtigte sicherlich nicht, die Naturgeschichte Buffon'scher Prägung und ihre Grundlagen in Frage zu stellen; doch legte er zweifellos seinen Finger in die Wunde einer mangelnden empirischen Basis europäischen Wissens und forderte insbesondere neuere Untersuchungen zur anthropologischen und kulturellen Vielfalt auf unserem Planeten, die von Vorurteilen der ,Daheimgebliebenen', der die außereuropäische Welt nicht bereisenden europäischen Philosophen, geschützt bleiben sollten.

1 Rousseau, Jean-Jacques: Discours sur l'origine et les fondements de l'inégalité parmi les hommes. In (ders.): Euvres complètes. Bd. III. Edition publiée sous la direction de Bernard Gagnebin et Marcel Raymond avec, pour ce volume, la collaboration de François Bouchardy, JeanDaniel Candaux, Robert Derathé, Jean Fabre, Jean Starobinski et Sven Stelling-Michaud. Paris: Gallimard 1975, S. 213. 
Dabei überrascht der frühe Zeitpunkt der Rousseau'schen Kritik, die lange vor der Berliner Debatte um die Neue Welt erfolgte. Sehen wir uns kurz die zentralen Kritikpunkte des Genfer Bürgersohns näher an! Nach der Erwähnung einiger weniger glaubwürdiger Berichte stellte er mit aller wünschenswerten Deutlichkeit fest:

\begin{abstract}
Von diesen Berichten einmal abgesehen, kennen wir die Völker in den weiten Regionen des Ostens nicht, die allein von Europäern frequentiert werden, die mehr darauf versessen sind, ihre Geldbörsen zu füllen als ihre Köpfe. [...] die ganze Erde ist bedeckt von Nationen, von denen wir nur die Namen kennen, und wir machen uns anheischig, das ganze Menschengeschlecht zu beurteilen! Nehmen wir an, dass ein Montesquieu, ein Buffon, ein Diderot, ein Duclos, ein D'Alembert, ein Condillac oder Männer von diesem Schlage Reisen unternähmen, um ihre Landsleute zu unterrichten, dass sie die Türkei, Ägypten, das Berberland, das Reich von Marokko, Guinea, die Kaffernländer, das Innere Afrikas und seine östlichen Küsten beobachteten und beschrieben, wie sie dies zu tun wissen [...]: dann in der anderen Hemisphäre dasselbe täten mit Mexiko, Peru, Chile, den Magellanischen Gebieten, ohne dabei die wahren oder falschen Patagonier zu vergessen [...]; nehmen wir an, dass diese neuen Herkules, zurück von ihren denkwürdigen Fahrten, im Anschluss nach Belieben die Naturgeschichte, die Sitten- und politische Geschichte dessen verfassten, was sie gesehen, so sähen wir selbst eine neue Welt unter ihren Federn erstehen, und so würden wir lernen, die unsrige zu kennen. ${ }^{2}$
\end{abstract}

Die Einschätzung des europäischen beziehungsweise französischen Wissensstandes über die Indes orientales wie die Indes occidentales, also die (Kolonial-) Gebiete im Osten wie im Westen Europas, könnte fataler kaum ausfallen. Gewiss, einige positive Ausnahmen europäischer Reiseberichte merkt der Genfer Philosoph in seiner umfangreichen Note zu seinem Second Discours durchaus an. Aber aufgrund ihrer alles beherrschenden persönlichen wie kommerziellen Interessen entgehen die meisten europäischen Reisenden mit ihren so zahlreichen, aber oft auch so ungesicherten und vor allem interessegeleiteten Berichten dem letztlich vernichtenden Urteil des Bürgers von Genf nicht.

Doch Rousseau stand der Gattung des Reiseberichts nicht etwa ablehnend gegenüber. Denn der Verfasser des Diskurses über die Ungleichheit leugnete die grundlegende Bedeutung der Reisen für die Ausweitung der menschlichen Kenntnisse und die umfassende Zirkulation von Wissen im europäisch-außereuropäischen Spannungsfeld keineswegs. Ganz im Gegenteil: Für ihn ging es darum, wohlvorbereitete Reisende, Philosophen (im Sinne des 18. Jahrhunderts) auszusenden, die nicht nur über ein Wissen (,savoir“), sondern mehr noch über ein „savoir faire“ und ein „savoir voir“ verfügten. Sie mussten in der Lage sein, nach ihrer Rückkehr nach Europa das, was sie gesehen hatten, ebenso an ihre

2 Ebda. 
Landsleute wie an ihr Lesepublikum innerhalb einer tendenziell weltumspannenden République des Lettres der Aufklärung weiterzugeben. Denn nur auf diese Weise sei es möglich, neue Grundlagen für ein neues Wissen zu schaffen, das nicht länger auf ungesicherten Grundlagen beruhen dürfe. Es gelte mithin, Männer vom Schlage eines Buffon, Condillac oder Diderot zu entsenden und diese vor Ort Untersuchungen durchführen zu lassen, welche den Kenntnisstand europäischer Wissenschaft auf ein deutlich höheres Niveau heben würden.

Die Vorstellungen Rousseaus sind von größter epistemologischer Tragweite: „Savoir faire“ und „savoir voir“ sollten auf diese Weise für die künftigen Leser des Reisenden in ein „savoir faire voir“ umschlagen. Dabei handelt es sich um ein Wissen und eine Technik des Vor-Augen-Führens, das nicht nur die europäische Sichtweise der Neuen Welt modifizieren und den „NouveauMonde“ in einen „monde nouveau“ verwandeln, sondern den Blick auch auf die europäischen Länder selbst grundlegend verändern könnte. ${ }^{3}$ Dabei dachte Rousseau ein durchaus dialektisches Verhältnis bei der internationalen Zirkulation von Wissen an: Fremderkenntnis impliziert stets Selbsterkenntnis - und mehr noch: Selbsterkenntnis ist ohne Fremderkenntnis nicht zu haben.

Ob Rousseau sich dieses Verhältnis wirklich als dialektischen Prozess dachte, kann man durchaus bestreiten oder in Frage stellen. Doch als ein Wechselverhältnis dachte sich der Verfasser des Discours sur l'inégalité diese weltumspannende Zirkulation von wissen sehr wohl. Im Übrigen kann nicht übersehen werden, dass innerhalb einer weltweiten - wenn auch zweifellos von Europa beherrschten - Relationalität die Kenntnisse reisender europäischer Philosophen auch für die Bewohner anderer Areas und Weltregionen von Nutzen sein mussten. Dies galt selbst unter den Bedingungen einer extremen Asymmetrie des Wissens. Rousseaus Argumente sind jener Ethik mit universalisierendem Anspruch verpflichtet, wie sie der (europäischen) République des Lettres zugrunde lag.

In der angeführten Passage erscheinen Sehen und Schreiben in ihrer Verbindung mit dem Reisen als komplementäre Handlungen, die in ihrer Abfolge einen Sinn (bezüglich) der Neuen Welt hervorbringen, den Rousseau dann auch zu glauben bereit wäre: „il faudra les en croire“ - dann müsse man ihnen eben glauben. ${ }^{4}$ Doch gründet dieser Glaube für Rousseau nicht auf dem Schreiben, der „écri-

3 Diese Überlegungen habe ich aus einer anderen Perspektive und mit Blick auf die Epistemologie von Auge und Ohr erstmals vorgestellt in Ette, Ottmar: Diderot et Raynal: l'œil, l'oreille et le lieu de l'écriture dans l',Histoire des deux Indes“. In: Lüsebrink, Hans-Jürgen / Strugnell, Anthony (Hg.): L',Histoire des deux Indes“: réécriture et polygraphie. Oxford: Voltaire Foundation 1996, S. 385-407.

4 Rousseau, Jean-Jacques: Discours sur l'origine et les fondements de l'inégalité parmi les hommes, S. 214. 
ture“ allein. Nicht die Bewegung des Diskurses, sondern die Bewegung des Reisens, das eine direkte Sicht auf die Dinge gewährt, jene Ortsveränderung also, die ein unmittelbares Sehen des Anderen ermöglicht, verleiht dem Schreiben über das Andere Autorität und damit erst eine Autorschaft im starken Sinne. Und in der Hierarchie der Sinne räumte Rousseau dem Gesichtssinn die erste Stelle ein: Er wollte sich als Augenzeuge nicht länger auf ein Hörensagen verlassen, das überdies von finanziellen Interessen gelenkt sei. Die Glaubwürdigkeit dieser Autorschaft ist in diesen Passagen des Second Discours folglich an die Legitimation durch eine Augenzeugenschaft zurückgebunden, die mit Blick auf das Wissen über weit entfernte Länder das eigene Reisen voraussetzt. Und überdies besaß Rousseau im Gegensatz zu anderen Philosophen keinerlei Aktien im lukrativen Geschäft mit dem transatlantischen Sklavenhandel.

Rousseau war in diesen Überlegungen zweifellos seiner Zeit voraus; und doch zog er lediglich die Bilanz bezüglich eines europäischen Wissens von der außereuropäischen Welt, das sich seiner Beschränktheit noch nicht einmal bewusst war. Es ist faszinierend, diesen Kritikpunkten zu folgen, die freilich noch weit entfernt von jeder Kritik am selbstverständlichen Eurozentrismus waren. Zugleich glimmt in diesen Überlegungen ein Gedanke auf, der für unsere Zeit, für unsere eigenen wissenschaftlichen und wissenschaftspolitischen Epistemologien (und ,Selbstverständlichkeiten`) von größter Aktualität und Dringlichkeit ist.

Denn über lange Zeit - und bis in unsere Gegenwart - hielt sich die Vorstellung, man habe die ,allgemeine‘, die generalisierende Theorie klar von den sogenannten Regionalwissenschaften, den Area Studies, als ,systematische“ oder systematisierende Wissenschaft abzutrennen, da letztere nur ein regional begrenztes Wissen - etwa über die Türkei, Nordafrika oder Südamerika, um bei den Beispielen Rousseaus zu bleiben - hervorzubringen in der Lage wären. Nichts aber ist - und auch dies wird die Berliner Debatte um die Neue Welt in der historischen Rückschau zeigen - anmaßender und den Gegenständen inadäquater als eine derartige Trennung. Denn es stellt sich selbstverständlich die Frage, anhand welcher Beispiele die allgemeine, die systematische Theorie sich universalistisch zu entwickeln vermag, kurz: worauf sie ihre Theorien beispielhaft gründet, um zu allgemeinen Schlüssen zu kommen.

Die Antwort auf diese zentrale Frage fällt erstaunlich einfach aus. Denn die vorgeblich ,allgemeine“ Theorie beruht zumeist auf äußerst lückenhaften Kenntnissen, die sich in der Regel auf das Wissen über einen mehr oder minder kleinräumigen und bestenfalls europäischen Ausschnitt beschränken, der ungerührt und unhinterfragt als normgebend gesetzt wird. So wird über die Entfaltung der Moderne ausgehend von den USA geschrieben, über die Entwicklung literaturtheoretischer Herausforderungen nur auf der Basis einer oder zweier europäischer Literaturen debattiert, werden Veränderungen in der Massenkultur 
nur am Beispiel westlicher Medien erörtert. Die Verallgemeinerung und Universalisierung deutscher, europäischer oder westlicher Modelle ist dabei ein in der westlichen Wissenschaftslandschaft völlig selbstverständlicher Prozess.

Um aber eine allgemeine Theorie adäquat fundieren und entwickeln zu können, ist schon aus wissenschaftstheoretischen und epistemologischen Gründen die Kenntnis verschiedenster Areas in den jeweiligen Sozial- und Geisteswissenschaften gänzlich unverzichtbar. Denn dann erst kann die Zielvorstellung Rousseaus greifen, unsere Welt in ihrer Gesamtheit auf neue Weise zu erfassen: „nous verrions nous mêmes sortir un monde nouveau de dessous leur plume, et nous apprendrions ainsi à connoître le nôtre. ${ }^{\text {5 }}$ Davor aber schützt sich nationale, europäische oder westliche Wissenschaft durch die Universalisierung jeweils der eigenen partikularen Exempel und Modelle.

Man könnte den ausführlich zitierten Überlegungen Rousseaus eine Passage aus der Feder des von ihm im obigen Zitat erwähnten Diderot an die Seite stellen, die erstmals ${ }^{6} 1780$ im elften Buch der dritten Ausgabe der Histoire philosophique et politique des établissements et du commerce des européens dans les deux Indes veröffentlicht wurde. Es handelt sich bei dieser Ausgabe um den letzten der drei genannten Bestseller des Siècle des Lumières, die wir in dieser Vorlesung analysieren und mit denen wir uns ausführlicher beschäftigen wollen.

Wenden wir uns, bevor wir uns dieser französischen Enzyklopädie der kolonialen Welt in ihrer Gesamtheit widmen, zunächst dieser aus der Feder von Denis Diderot stammenden und unter dem Namen von Guillaume-Thomas Raynal veröffentlichten Beobachtung zu. In gewissem Sinne handelt es sich um eine Antwort und mehr noch um eine scharfsinnige erkenntnistheoretische Replik fünfundzwanzig Jahre nach der Veröffentlichung von Rousseaus zweitem Discours. Zu Beginn von Rousseaus Überlegungen findet sich seine Klage darüber, niemals „deux hommes bien unis, riches, l'un en argent, l'autre en génie, tous deux aimant la gloire“ gefunden zu haben; einen Ruhm, für den der eine bereit wäre, „zwanzigtausend Taler“ zu opfern, der andere „zehn Jahre seines Lebens“ zugunsten einer erfolgreichen Reise um die Welt. ${ }^{7}$ Uns interessiert hier nicht die bemerkenswerte Beziehung zwischen den Zahlenangaben, sondern die Tatsache, dass Diderot die diskursive Struktur dieser Passage wiederauf-

5 Ebda., S. 213.

6 Vgl. Duchet, Michèle: Diderot et l'Histoire des Deux Indes ou l'Ecriture Fragmentaire. Paris: Nizet 1978, S. 84.

7 Rousseau, Jean-Jacques: Discours sur l'origine et les fondements de l'inégalité parmi les hommes. S. 213. 
nahm, um zugleich ihrem kritischen Sinn eine neue Wendung zu geben: „Der reiche Mann schläft und der Gelehrte wacht; doch er ist arm. Seine Entdeckungen sind den Regierungen zu gleichgültig, als dass er Hilfsmittel beantragen oder Dank und Entschädigung erhoffen dürfte. Man würde unter uns mehr als einen Aristoteles finden; aber wo ist der Monarch, der ihm sagen würde: Meine Macht steht zu Deiner Verfügung [...].“8

Ein Vierteljahrhundert nach dem Erscheinen des zweiten Discours Rousseaus ist die Verbindung zwischen dem Reichen und dem Genie, zwischen dem Monarchen und dem Gelehrten nicht realistischer geworden. Wissenschaft und Forschung sind stets auf die Unterstützung eines reichen Mäzens oder eines Staates angewiesen - daran hat sich wenig geändert. Anders als Rousseau, der am liebsten einen Buffon, Duclos, D’Alembert oder Condillac, aber auch einen Diderot auf eine Weltreise geschickt hätte, war der Co-Autor von Guillaume-Thomas Raynals Histoire des deux Indes in keiner Weise dazu bereit, sein Arbeitszimmer in Paris zu verlassen und die Welt zu umsegeln. Und in einer Passage aus seiner Feder führte er hierzu keineswegs persönliche, sondern epistemologische Gründe an: „Der Beobachter, der homo contemplativus, ist sesshaft; \& der Reisende ist ignorant oder ein Lügner. Wem das Genie zuteil wurde, verachtet die kleinlichen Details der Erfahrung; \& derjenige, der die Erfahrungen und Experimente macht, ist fast immer ohne jedes Genie.“9

Bei Rousseau basiert das Wissen auf dem Sehen, das „sa-voir“ auf dem „voir“. Bei ihm liegt der Fokus auf der Augenzeugenschaft, auf der direkten eigenen Erfahrung, wodurch gleichzeitig der Gesichtssinn privilegiert wird. ${ }^{10}$ Ist die Verbindung zwischen dem mit Geld und dem mit Genie gesegneten Menschen zufälliger Natur, so ist die Einheit zwischen dem Philosophen und dem

8 Raynal, Guillaume-Thomas: Histoire philosophique et politique des établissements et du commerce des européens dans les deux Indes. Tome cinquième. Genf: Chez Jean-Léonard Pellet, Imprimeur de la Ville \& de l'Académie 1781, S. 43: „L'homme riche dort; le savant veille; mais il est pauvre. Ses découvertes sont trop indifférentes aux gouvernemens pour qu'il puisse solliciter des secours ou espérer des récompenses. On trouveroit parmi nous plus d'un Aristote; mais où est le monarque qui lui dira: ma puissance est à tes ordres [...].“

9 Raynal, Guillaume-Thomas: Histoire philosophique et politique des établissements et du commerce des européens dans les deux Indes. Tome cinquième. Genf: Chez Jean-Léonard Pellet, Imprimeur de la Ville \& de l'Académie 1781, S. 43: „L'homme contemplatif est sédentaire; \& le voyageur est ignorant ou menteur. Celui qui a reçu le génie en partage, dédaigne les détails minucieux de l'expérience; \& le faiseur d'expériences est presque toujours sans génie.“

10 Vgl. zur Hierarchie der Sinne in der Beschäftigung mit der außereuropäischen Welt Ette, Ottmar: Diderot et Raynal: l'œil, l'oreille et le lieu de l'écriture dans l'„Histoire des deux Indes“. In: Lüsebrink, Hans-Jürgen / Strugnell, Anthony (Hg.): L',Histoire des deux Indes“: réécriture et polygraphie. Oxford: Voltaire Foundation 1996, S. 385-407. 
Reisenden, zwischen „philosophe“ und „voyageur“ für Rousseau bewusst und konzeptionell fundiert: Sie ist erkenntnistheoretisches Programm.

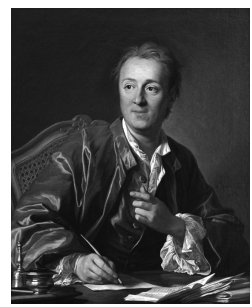

Abb. 33: Louis-Michel Van Loo: Denis Diderot (1713-1784).

Bei Denis Diderot finden wir zwar die Spaltung zwischen dem Mächtigen und dem Gelehrten wieder, doch unternimmt dieser „savant“ keine physischen Reisen, sind seine Bewegungen doch rein geistiger Natur: Denn der Gelehrte reist nicht. Diderot weist ihm einen Ort zu, den er nicht verlassen wird: Der Ort des Arbeitens und der Ort des Schreibens unterscheiden sich in einem rein räumlichen Sinne nicht voneinander. Dem homo contemplativus stellt Diderot nicht den homo faber, sondern den Reisenden, eine Art homo migrans, gegenüber, der entweder unter einem Mangel an Wissen (,ignorant“) oder unter einem Mangel an Wahrheit und Wahrhaftigkeit (,menteur“) leide und daher für Diderot in einem System hierarchisierter Wissenszirkulation auf eine bestenfalls zweitrangige Bedeutung herabgestuft werden muss.

Diese Herabstufung hat weitreichende epistemologische Konsequenzen. Denn damit werden zugleich der Vorrang der Augenzeugenschaft, der Vorrang des eigenen Sehens und die empirische Fundierung allen Wissens aufgegeben. „A beau mentir qui vient de loin“ - und man könnte aus heutiger Sicht fast glauben, dieses Sprichwort sei auch geprägt worden für jene Wissenschaften, die vor wenigen Jahren von einem ansonsten renommierten Berliner Wissenschaftshistoriker einmal ein wenig unglücklich als „Fernwissenschaften“ bezeichnet wurden. Diese Bezeichnung macht innerhalb der bundesrepublikanischen Wissenschaftslandschaft nur insofern Sinn, als diese Wissenschaften fernab der als sinnvoll erachteten Bereiche des wissenschaftlichen Main Stream liegen. Mit Blick auf die Ergebnisse, welche diese „Fernwissenschaften“ liefern, sind sie freilich weit davon entfernt, hinter den ,naheliegenden' Wissenschaften zurückzustehen.

Doch bleiben wir im 18. Jahrhundert! Denn die in der Folge zu schildernden Debatten sind selbst noch für unsere Gegenwart von großer Bedeutung. Nicht umsonst ließ Denis Diderot die Dialogpartner seines Supplément au voyage de Bougainville darüber debattieren, ob der berühmte französische Entdeckungsreisende bei seiner Weltumsegelung nicht eher ein sesshafter Bewohner auf 
den Planken seines schwimmenden Hauses („maison flottante“11) gewesen sei. Dagegen müsste der Leser von Bougainvilles berühmtem Reisebericht als der eigentliche Weltreisende betrachtet werden, sei er es doch, der - scheinbar unbeweglich auf den Dielen seines fest gebauten Hauses - kraft seiner Lektüre die Welt umrundet habe. ${ }^{12}$ Man könnte hier mit guten Gründen gewiss nicht von einem Diderot‘schen „paradoxe sur le comédien“, wohl aber vom Paradox über den Reisenden, vom „paradoxe sur le voyageur“ sprechen, welcher in seiner höchsten Form der Leser ist - und wäre er ein Leser des Buches der Welt. ${ }^{13}$ Doch mit diesem spannenden Aspekt haben wir uns bereits in der Vorlesung über das ReiseSchreiben und die Reiseliteratur ausführlich auseinandergesetzt. ${ }^{14}$

An dieser Stelle kann die Tatsache nicht ausführlich erörtert werden, dass die epistemologisch so relevante Scheidung zwischen den Reisenden und den Daheimgebliebenen keineswegs eine Erfindung des 18. Jahrhunderts war. Denn sie zieht sich bereits seit der ersten Phase beschleunigter Globalisierung durch den gesamten abendländischen Diskurs über die Neue Welt und war im Übrigen bereits in der Antike hinsichtlich des Zusammenspiels von Auge und Ohr als Quellen der Information über eine unbekannte Welt präsent. ${ }^{15}$ Doch sei darauf verwiesen, dass jenseits des hier markierten und in der Tat markanten epistemologischen Gegensatzes zwischen Rousseau und Diderot die beiden großen Philosophen der europäischen Aufklärung in einem nicht unwesentlichen Punkt miteinander übereinstimmen. Denn der reisende Philosoph, der „philosophe voyageur" Rousseaus, wählt ganz wie der sesshafte homo contemplativus Diderots denselben Ort, um sein Werk niederzuschreiben: den europäischen Schreibtisch. Er bleibt als Ort der Macht und als Ort des Wissens über die außereuropäische Welt von beiden europäischen Philosophen unangetastet.

Das hermeneutische Bewegungsmuster der Reise beruht für beide europäische „philosophes“ als Verstehensprozess stets auf einem Kreis. Von Europa geht die Reise aus, wird am europäischen Schreibtisch konzipiert, und nach Europa führt die Reise zurück, wird am europäischen Schreibtisch durch die Nie-

11 Diderot, Denis: Supplément au Voyage de Bougainville ou Dialogue entre A et B. In (ders.): Oeuvres. Edition établie et annotée par André Billy. Paris: Gallimard 1951, S. 964.

12 Vgl. hierzu Ette, Ottmar: „Le tour de l'univers sur notre parquet“: lecteurs et lectures dans l'„Histoire des deux Indes“. In: Bancarel, Gilles / Goggi, Gianluigi (Hg.): Raynal, de la polémique à l'histoire. Oxford: Voltaire Foundation 2000, S. 255-272.

13 Vgl. Blumenberg, Hans: Die Lesbarkeit der Welt. Frankfurt am Main: Suhrkamp 1986.

14 Vgl. den Auftaktband der Reihe „Aula“ in Ette, Ottmar: ReiseSchreiben. Potsdamer Vorlesungen zur Reiseliteratur (2020).

15 Vgl. zu diesen Zusammenhängen umfassender das dritte Kapitel in Ette, Ottmar: Literatur in Bewegung. Raum und Dynamik grenzüberschreitenden Schreibens in Europa und Amerika. Weilerswist: Velbrück Wissenschaft 2001. 
derschrift eines Reiseberichts zur Vollendung geführt. Und so ist es auch keineswegs zufällig, dass Rousseau in der oben angeführten Passage von einer Reise um die Welt spricht: Schon die Reise des Christoph Kolumbus machte nur dadurch Sinn, dass sie den Genuesen nach Europa zurückführte und in einem Admiral verwandelte. Die großen Forschungsreisen des 18. Jahrhunderts wie etwa diejenigen von Bougainville, Cook oder La Pérouse waren allesamt Reisen um die Welt und stehen mit ihren hermeneutischen Bewegungen für die zweite Phase beschleunigter Globalisierung ein.

Ist der reisende Philosoph erst einmal nach Hause zurückgekehrt und aufgrund seiner Mühen und seines Leidens in einen ,neuen Herkules' verwandelt, wird er sich bald an seinen Schreibtisch setzen und seine Ansichten niederschreiben. Er tut dies aus einer europäischen Perspektive, die zugleich eine Universalisierung seines Wissens miteinschließt. Dass die Niederschrift des Textes, die eigentliche Textproduktion ,selbstverständlich“ nicht in Übersee, sondern in Europa erfolgt, erscheint beiden Europäern an ihren europäischen Schreibtischen als geradezu natürlich. Denn der Ort des Schreibens kann als Ort der Wissensproduktion innerhalb eines zutiefst asymmetrischen Zirkulationssystems von Wissen nur in Europa angesiedelt sein: Kein anderer Ort dieser Welt käme dafür in Frage. Das Lesen im Buch der Natur mag oder muss weltweit erfolgen; die Niederschrift dieser Lektüre der Natur aber kann - dies braucht weder ein Rousseau noch ein Diderot zu thematisieren - ,natürlich“ nur in den europäischen Zentren des Wissens erfolgen. Die ganze Welt mag ein Reich der Zeichen sein: Europa aber versteht sich als das Reich des Wissens eines Wissens, das diese weltweiten Zeichen zu deuten vermag.

Innerhalb der hier von Jean-Jacques Rousseau und Denis Diderot skizzierten Problematik der Beziehung zwischen Reisen und Wissen sowie Reisen und Schreiben situiert sich auch die Berliner Debatte um die Neue Welt, die als ein eminent wichtiger Teil des von Antonello Gerbi in einer längst kanonisch gewordenen Studie so bezeichneten Disputs um die Neue Welt ${ }^{16}$ angesehen werden muss. Wir haben bereits aus der Perspektive des Cornelius de Pauw einiges von dieser weltweit geführten Debatte gehört, aber diese vielleicht wichtigste in Berlin im Aufklärungszeitalter geführte Auseinandersetzung noch nicht als eine vielstimmige Gesamtheit erkundet. ${ }^{17}$ Dies wollen wir jetzt in unserer Vorlesung nachholen!

\footnotetext{
16 Vgl. Gerbi, Antonello: La disputa del nuovo mondo. Storia di una polemica: 1750-1900. Nuova edizione a cura di Sandro Gerbi. Con un profilo dell'autore di Piero Treves. Mailand Neapel: Riccardo Ricciardi editore 1983.

17 Vgl. hierzu auch Ette, Ottmar: Die „Berliner Debatte“ um die Neue Welt. Globalisierung aus der Perspektive der europäischen Aufklärung. In: Bernaschina, Vicente / Kraft, Tobias / Kraume, Anne (Hg.): Globalisierung in Zeiten der Aufklärung. Texte und Kontexte zur „Berliner
} 
Die Berliner Debatte um die Neue Welt hatte viele Disputanten, deren Positionen in der Folge nicht in allen Einzelheiten dargestellt werden können. ${ }^{18}$ Einer der beiden wichtigsten Protagonisten dieser nicht nur in Europa, sondern auch in Übersee mit größter Aufmerksamkeit registrierten und kommentierten Berliner Debatte, Antoine-Joseph Pernety, war einst in der Funktion eines Schiffskaplans mit keinem Geringeren als Bougainville zwar nicht um die gesamte Erdkugel, wohl aber in die einst von Amerigo Vespucci so genannte „Neue Welt“ gereist. Diese Tatsache sollte in jenen Auseinandersetzungen, die in der aufstrebenden Hauptstadt des ehrgeizigen Preußenkönigs Friedrich II. ihren Ausgang nahmen, aber rasch auf ein weltweites Echo stießen, eine wichtige Rolle spielen. Uns interessieren im Kontext unserer Vorlesung über die Aufklärung zwischen zwei Welten weniger die unterschiedlichen Positionen einzelner Vertreter der Debatte als vielmehr die grundlegenden epistemologischen Enjeux, um die es in dieser Debatte ging. Denn sie wirft nicht nur ein Licht auf die Problematik der Aufklärung in verschiedenen Ländern Europas sowie auf die République des Lettres, sondern auf ein Aufklärungszeitalter, das längst transatlantische Dimensionen angenommen hatte.

Pernety ist dabei ein überaus interessanter Aufklärer, auf den sich die internationale Forschung stärker konzentrieren sollte. Viele seiner Tätigkeiten am Hofe Friedrichs des Großen, aber auch und vor allem in dessen Berliner Akademie liegen noch im Dunkeln. Zu lange hat sich die Aufklärungsforschung mit bestenfalls europäischen Fragestellungen beschäftigt und musste darüber die weltumspannenden Dimensionen vernachlässigen. Mit einigen der zentralen Fragen aufklärerischer Anthropologie, aber auch mit den hier dargestellten Problemen wahrnehmungstheoretischer Epistemologie beschäftigte sich der früher von der Inquisition in Avignon verfolgte und nach Preußen geflüchtete Benediktiner Antoine-Joseph Pernety bereits in seinem 1769 in französischer Sprache zu Berlin erschienenen Journal historique. Auf dessen Titelseite bezeichnete er sich stolz als „Membre de l'Académie Royale des Sciences \& Belles-Lettres de Prusse“ und als „Bibliothécaire de Sa Majesté le Roy de Prusse“ und berichtet von seiner Reise unter der Leitung von LouisAntoine de Bougainville zu den tropischen Küsten des heutigen Brasilien, zu den Malwinen-Inseln und an die Südspitze des amerikanischen Kontinents. ${ }^{19}$

Debatte“ um die Neue Welt (17./18. Jh.). Teil 1. Frankfurt am Main - Bern - New York: Peter Lang Edition 2015, S. 27-55.

18 Vgl. hierzu die beiden Bände von Bernaschina, Vicente / Kraft, Tobias / Kraume, Anne (Hg.): Globalisierung in Zeiten der Aufklärung. Texte und Kontexte zur „Berliner Debatte“ um die Neue Welt (17./18. Jh.). 2 Bde. Frankfurt am Main - Bern - New York: Peter Lang Edition 2015, S. $27-55$. $19 \mathrm{Vgl}$. Pernety, Antoine-Joseph: Journal historique d'un Voyage aux Iles Maloü̈es en 1763 \& 1764, pour les reconnoître, \& y former un établissement; et de deux Voyages au Détroit de Magellan, avec une Relation sur les Patagons. 2 Bde. Berlin: Etienne de Bourdeaux 1769. 
In seinem Journal betonte Pernety immer wieder die grundsätzliche Andersartigkeit der Neuen Welt. So schilderte er auch auf nicht weniger als zwanzig Seiten die am 10. November 1763 erfolgte Querung des Äquators und damit jene Szenerie, die sich so oder in vergleichbarer Form auf allen französischen wie europäischen Schiffen vollzog, welche die Äquatoriallinie, den Zentralbereich des Tropengürtels, passierten und in eine andere Hemisphäre eintraten. Längst waren die Tropen für die europäischen Seefahrtnationen zum planetarischen Bewegungs-Raum par excellence geworden, ${ }^{20}$ doch stellten sie damit zugleich den Schwellenbereich eines Übergangs dar, den man bei diesem sich auf Süd-Kurs nach Brasilien befindenden Schiff als einen symbolträchtigen Übergang von der östlichen in die westliche Hemisphäre, gleichzeitig aber auch von der nördlichen auf die südliche Halbkugel beschreiben darf. Diesen doppelten Übergang markiert der Reisebericht des Franzosen auf durchaus eindrückliche Weise.

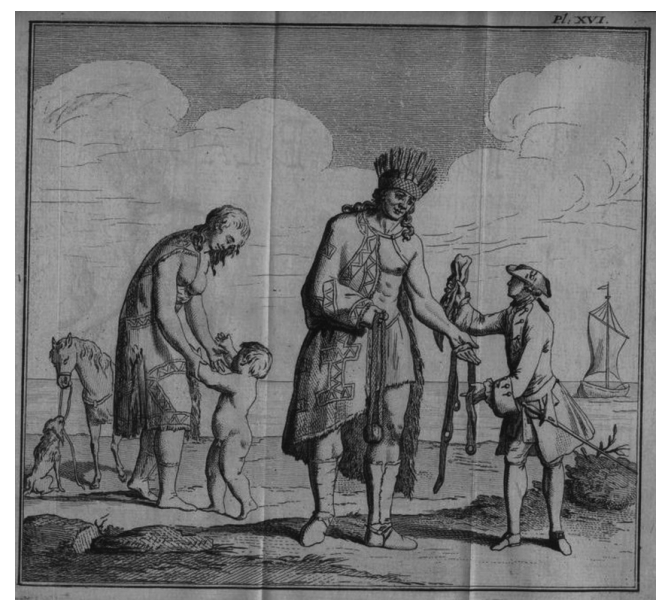

Abb. 34: Darstellung von Antoine-Joseph Pernety (1716-1796) bei den Patagonen.

Pernetys ausführliche Darstellung des „Baptême de la ligne“21 beginnt noch in der glühenden Mittagshitze an Deck des französischen Schiffes mit der Aufstel-

20 Vgl. hierzu Ette, Ottmar: Diskurse der Tropen - Tropen der Diskurse: Transarealer Raum und literarische Bewegungen zwischen den Wendekreisen. In: Hallet, Wolfgang / Neumann, Birgit (Hg.): Raum und Bewegung in der Literatur. Die Literaturwissenschaften und der Spatial Turn. Bielefeld: transcript Verlag 2009, S. 139-165; dort habe ich mich bereits mit dieser zuvor wohl noch nicht behandelten Darstellung der sogenannten Äquatortaufe auseinandergesetzt. 21 Pernety, Antoine-Joseph: Journal historique d'un Voyage aux Iles Maloü̈nes en 1763 \& 1764, Bd. 1, S. 95. 
lung eines Beckens mit Meerwasser, eines Throns für den „Seigneur Président de la Ligne“ sowie weiterer Sitzgelegenheiten für den „Chancelier“ und den (aus Sicht des „aumônier“ sicherlich besonders interessanten) „Vicaire“ nebst einer Versammlung der gesamten Mannschaft und aller Passagiere. ${ }^{22}$ Detailreich und nicht ohne literarisches Geschick wird anschließend der zeremonielle und rituelle Charakter dieser Äquatortaufe hervorgehoben.

Die Tropen waren für die abendländische Welt von jeher ein Faszinosum und diese Querung der Äquatoriallinie stellt vergleichbar mit dem Zeit-Raum des Karnevals die ,natürlichen“ Hierarchien gleichsam auf den Kopf und bildet einen ,monde à l'envers“. Dies ist eine Tatsache, die das karnevaleske Element mit der Vorstellung der Antipoden - einer Welt, deren Bewohner buchstäblich auf dem Kopf stehen und in der die Bäume nach unten wachsen - zu verbinden scheint. Dem vorwiegend europäischen Lesepublikum wird auf diese Weise anschaulich vor Augen geführt, dass es dem Reisenden in eine andere, in eine fremde Welt folgt, die über einen eigenen Zeichenvorrat verfügt und nicht mit den Maßstäben Europas gemessen werden kann. Nichts scheint in dieser ,anderen' Welt gleich zu sein, alles muss sich hier notwendig unterscheiden. Es lohnt daher, der literarischen Ausgestaltung dieser Szenerie, die zweifellos den reiseliterarischen Ort eines Höhepunkts von Pernetys Journal historique markiert, etwas Aufmerksamkeit zu schenken.

Mit der Reise in die Tropen tauchen wir also in eine andere Welt ein. Die kolonialen Tropengebiete sind daher von Europa nicht allein durch die ökonomischen oder sozialen, politischen oder juristischen Grenzen getrennt: Diese Trennlinie verläuft auch und vor allem durch das Symbolische. Ohne die von Pernety entworfene literarische Szene in all ihren Details wiedergeben zu können, ist es doch aufschlussreich zu beobachten, dass die Inszenierung einer Gegen-Ordnung, die für einen Tag zwischen den Wendekreisen symbolisch in Kraft tritt, jene Wendungen und Wandlungen vorführt, welche die Tropen als gegenüber Europa andere Welt im Zeichen der Trennlinie des Äquators repräsentieren. Sie sind in diesem Sinne auch rhetorisch eine andere Figuration des Planetarischen.

Die karnevalesken Züge der Szenerie sind unübersehbar, betritt doch zunächst - selbstverständlich mit dem Einverständnis Kapitän Bougainvilles ein von sechs Schiffsjungen sekundierter und in einen Schafspelz gehüllter und bemalter Matrose die Bühne, dessen Verkleidung und Verwandlung präzise beschrieben wird, ${ }^{23}$ bevor der ebenfalls in Schafsfelle gekleidete „bon-homme de la Ligne“ höchstselbst, umgeben von seinem herausgeputzten Hofstaat, das Kommando an Bord übernimmt. Das Schauspiel travestierter Alterität beginnt.

22 Ebda., Bd. 1, S. 96.

23 Ebda., Bd. 1, S. 98 f. 
Inwieweit diese andere Ordnung aus einer ihrerseits nicht unterlaufenen patriarchalischen Perspektive zugleich auf das ,andere“ Geschlecht projiziert wird, mag das folgende Zitat der fruchtbaren ,Versprechen` des Kapitäns Louis-Antoine de Bougainville belegen:

Nachdem die Dinge so angeordnet waren, sagte der Vikar Herrn von Bougainville: „Um in die noble \& mächtige Gesellschaft des Herren Präsidenten der Äquatoriallinie aufgenommen zu werden, muss man vorab bestimmte Verpflichtungen eingehen, von denen Sie versprechen müssen, sie auch einzuhalten. Diese Verpflichtungen haben nur vernünftige Dinge zum Ziele. Zum Glücke, antwortete Herr von Bougainville. Versprechen Sie, erwiderte darauf der Vikar, ein guter Bürger zu sein \& zu diesem Behufe an der Bevölkerung zu arbeiten \& folglich die Mädchen nicht ruhen zu lassen, und zwar immer dann, wenn sich eine günstige Gelegenheit ergibt? - Ich verspreche es.“24

Der Einbau dieser Passage wirft ein deutliches Licht darauf, auf welchen Ebenen sich die europäischen Kolonialherren nun einer eigenen Gesetzlichkeit verpflichtet fühlten. Mit der Überschreitung der Äquatoriallinie wussten sie sich in einer anderen Welt, in welcher sie selbst die absoluten Herrscher waren. Denn in den Tropen ging es für die männlichen europäischen Kolonialherren nicht nur darum, das Land und die Ländereien militärisch zu unterwerfen und auszubeuten, sondern auch sexuell zur eigenen Lusterzeugung auszuplündern und überdies noch künftige Sklaven zu zeugen.

In dieser Szenerie wird gleichsam ein Versprechen eingeholt, welches nicht allein eine große sexuelle Freizügigkeit der männlichen Besatzungen in der Neuen Welt beinhaltet, sondern zugleich auch eine männliche Unterwerfung der weiblich gegenderten Kolonien symbolisiert. Sexueller Missbrauch und die sexuelle Ausbeutung junger Frauen, dies wissen wir aus allen Kolonialakten, erschienen als selbstverständlich und waren völlig an der Tagesordnung. In der Neuen Welt galten folglich für die Männer andere Formen und Normen der Konvivenz, die ganz unverkennbar die männliche Potenz ins Zentrum jeglicher Geschlechterordnung rücken. Dies war zwar nicht von den patriarchalischen Gesellschaftssystemen in den Herkunftsländern verschieden, lässt aber erkennen, dass die phallozentrische Geschlechterordnung ohne alle Rücksichtnahme ausgelebt werden konnte.

Damit werden beim Übertritt von der einen in die andere Hemisphäre schon einmal klar die männlich zentrierten Unterwerfungswünsche vorformuliert und fixiert. Es ist, als würde in diesem Akt auf einer symbolischen Ebene die Inbesitznahme einer neuen Welt, wie sie am Ausgang des 15. Jahrhunderts bei Kolumbus in einer genau festgehaltenen juristischen Vorgehensweise abgespult wurde, nun für die Geschlechterordnungen definiert. Auch im Auf-

24 Ebda., Bd. 1, S. $107 \mathrm{f}$. 
klärungszeitalter gilt diese Geschlechterordnung fort, in der zwischen zwei Geschlechtern, einem herrschenden und einem beherrschten, klar unterschieden wird. Wir sehen also, welch eminent politische und symbolische Bedeutung die Geschlechterbeziehungen im Reisebericht wie in der Wirklichkeit - einmal in die Neue Welt projiziert - besitzen. Der militärischen, sozialen und kulturellen Unterwerfung folgt unmittelbar eine sexuelle, welche am Phallogozentrismus dieser ,aufgeklärten‘ Kolonialgesellschaften keinerlei Zweifel lässt.

Doch die von Pernety literarisch nachgestaltete Szenerie an Bord der Fregatte unter dem Kommando des renommierten und erfahrenen Kapitän Bougainville erzählt uns noch mehr. Die Serie von Versprechen, die mit einem Schwur und einer ritualisierten Taufszene abgeschlossen wird, in der aus christlicher Sicht stets die Symbolik des Beginns eines anderen Lebens gegenwärtig ist, eröffnet eine Abfolge weiterer Lustbarkeiten. Bei diesen dürfen auch zwei paradiesische „Demoiselles Acadiennes“ ${ }^{25}$ sowie allerlei neckische Spiele nicht fehlen, die sich in der Folge auf Bougainvilles Fregatte unter dem Kommando des „bon-homme de la Ligne“ abspielen. Die Projektion männlich beherrschter sexueller Freizügigkeit auf die Tropen, auf die ,andere‘ Welt, zählt zum Kernbestand europäischer Bilderwelten von fernen Ländern. Denn diese Neue Welt erscheint in ihrer unterworfenen und immer wieder von neuem zu unterwerfenden Form in weiblicher Repräsentation. Blicken wir uns heute in den Katalogen der Veranstalter von Fernreisen in die Karibik oder nach Thailand um, so wird deutlich, dass derlei Traditionen keineswegs verloren gegangen sind, sondern noch immer einen notwendig gezügelten - Bestandteil des europäischen Blicks auf außereuropäische Welten darstellen.

So werden von europäischen Sexualphantasien geprägte Erörterungen über die Geschlechtlichkeit und das Geschlechtsleben der indigenen Bevölkerungen nicht von ungefähr auch in der Berliner Debatte über die Neue Welt eine wichtige Rolle spielen. Wir sollten uns dies stets vor Augen halten: Die koloniale Unterwerfung wird auch genderspezifisch umgesetzt und geht ein in die phallokratischen Selbstdarstellungs- und Verhaltensweisen europäischer Kolonialherren! In diesem Zusammenhang werden in den Amerikas die ,Indianer“ im Gegensatz zu den lasziven ,Indianerinnen', die sich nur so nach Europäern sehnen, zu impotenten Eunuchen degradiert, die es an sexueller Potenz mit den europäischen Männern niemals aufnehmen könnten. Gewiss lassen sich zwischen den einzelnen europäischen Kolonialländern signifikante kulturelle Unterschiede auf diesem Gebiet beobachten; doch stellen diese Unterschiede nur Nuancen innerhalb der kolonialen Unterwerfung dar.

25 Ebda., Bd. 1 S. 109. 
All dies ist ein symbolischer Akt mit Folgen, die sich selbstverständlich nicht allein in Bezug auf die Geschlechterordnungen auswirken. Innerhalb der narrativen Abfolge des Journal historique schärft die ausführliche Darstellung der Äquatortaufe die Aufmerksamkeit des Lesepublikums für die diskursive (und epistemologisch grundlegende) Andersartigkeit der ,anderen` Welt. Die Neue Welt wird, wie schon zu Beginn der sogenannten ,Entdeckung 'Amerikas, auch noch im Aufklärungszeitalter als radikale Alterität projiziert: Die Question de l'autre, ${ }^{26}$ die Frage nach dieser Alterität, beherrscht alle Bereiche, nicht allein den geschlechtlichen. Denn zwischen den Kapverden und der brasilianischen Küste quert die Fregatte nicht nur die Äquatoriallinie, sondern tritt mit ihrer Besatzung und ihren Passagieren symbolisch in eine andere Welt, in ein für die französische Besatzung neues Leben ein. Nichts bleibt, wie es war: Selbst die innerhalb der europäischen Hierarchien Untersten können sich, wie etwa Matrosen oder einfache Schiffsjungen, in den Tropen als kleine Herrscher aufführen.

Entscheidend ist nicht, dass sich die Formen der Taufe von Nation zu Nation, aber auch von Schiff zu Schiff unterscheiden; ausschlaggebend ist vielmehr die Tatsache, dass dieses „Baptême“ stets an Bord durchgeführt wird und ein verbrieftes Recht der Mannschaften darstellt. ${ }^{27}$ Dabei ist die Taufe nicht vorrangig an die Querung der Äquatoriallinie selbst, sondern an den Eintritt in die Zone der Wendekreise gebunden, wie Pernety in seinem schönen Reisebericht abschließend erläutert:

Wenn das Schiff auf seiner Fahrt nicht die Äquatoriallinie, sondern nur die Tropen quert, sind diejenigen von der Mannschaft, die bereits dort waren, aber nicht ihr Tributrecht verlieren wollen, darauf gekommen, den Tropenbereich als den ältesten Sohn des Kerls der Äquatoriallinie und den folgerichtigen Erben seiner Rechte zu nennen. Sie führen folglich bei der Querung der Tropen dieselbe Farce wie die unter dem Äquator auf. ${ }^{28}$

Dieser Zusatz macht deutlich, dass es sich um ein Recht der Mannschaften handelt und damit auch symbolisch ein Teil der Macht auf die im Grunde Unterprivilegierten unter den Europäern übergeht. Zumindest ein Teil von diesem karnevalesken „monde à l'envers“, von dieser Welt auf dem Kopf, wird eingelöst. So stellen die Tropen als weltumspannender Bewegungs-Raum den ,eigentlichen` dynamischen Kern europäischer Alteritätsvorstellungen dar. In den Tropen scheint wenn nicht alles, so doch vieles erlaubt. Tropen sind sie folglich in einem dreifachen Sinne: als Raum der Bewegungen (der Sonne zwischen den Wendekreisen) und als Bewegungsraum (der Europäer in ihren transozeanischen Verbindungen), zugleich

26 Vgl. Todorov, Tzvetan: La conquête de l'Amérique. La question de l'autre. Paris: Seuil 1982.

27 Pernety, Antoine-Joseph: Journal historique, Bd. 1, S. 111.

28 Ebda., Bd. 1, S. 112. 
aber auch als Tropen in einem rhetorisch-literarischen Sinne, in welchem die übertragenen, projizierten Bedeutungen vorherrschen und bestimmend sind. ${ }^{29}$

Dass diese gerade auch religiöse Elemente karnevalisierende Szenerie in der Folge freilich ebenso auf andere ,Grenzlinien' übertragen wurde und - wie etwa die rituelle „Polartaufe“ an Bord des deutschen Forschungsschiffs Polarstern noch heute zeigen kann - auch in unseren Tagen an Bord vieler Schiffe gefeiert wird, vermindert keineswegs die anhand dieser „rites de passage“ erkennbar werdende symbolische Bedeutung der Bewegungsfigur der Tropen. Denn diese abendländisch entworfenen Tropen sind Tropen der Verwandlung, der Metamorphose, in denen der Transfer von einer ,Alten' in eine ,Neue' Welt mit einer fundamentalen Transformation aller Sitten, Gewohnheiten und Lebensverhältnisse einhergeht. Allerdings stets nach den Regeln der Europäer: Die karnevaleske Welt auf dem Kopf bedeutet gerade nicht, dass die Kolonisierten und sei es auch nur für wenige Stunden - die Macht zurückerhielten. Die Neue Welt ist in den europäischen Reiseberichten des 18. Jahrhunderts eine andere Welt, die von der Alten Welt als klar geschiedene Gegen-Welt re-präsentiert wird.

Diese Andersheit der Tropen und des tropischen Amerika steht im europäischen Wissenschaftsdiskurs nur allzu oft im Zeichen einer fundamentalen Inferiorität, einer Unterlegenheit, die sich auf alle Bereiche von Natur und Kultur in den Amerikas bezieht. In der zweiten Hälfte des 18. Jahrhunderts, während der zweiten Phase beschleunigter Globalisierung, mögen sich auch die historischen Kontexte gewandelt haben. An die Stelle der iberischen Mächte sind längst Frankreich und England als globalisierende Führungsnationen getreten. Doch jene Tropen, die aus europäischer Perspektive den Blick auf die Tropen bestimmen, finden sich weitgehend unverändert in den Schriften der „philosophes“ der europäischen Aufklärung. Und weit darüber hinaus, bis in unsere Tage ...

Ohne über einen längeren Zeitraum jemals Gehör in Europa zu finden, wehrten sich amerikanische Aufklärer wie der neuspanische Jesuit Francisco Javier Clavijero, ${ }^{30}$ mit dem wir uns bereits ausführlich beschäftigt haben, vehement und mit guten Gründen dagegen, in der Nachfolge Buffons von der zeitge-

29 Vgl. auch Ette, Ottmar: Diskurse der Tropen - Tropen der Diskurse: Transarealer Raum und literarische Bewegungen zwischen den Wendekreisen. In: Hallet, Wolfgang / Neumann, Birgit (Hg.): Raum und Bewegung in der Literatur. Die Literaturwissenschaften und der Spatial Turn. Bielefeld: transcript Verlag 2009, S. 139-165.

30 Vgl. das zunächst im italienischen Exil in italienischer Sprache erschienene Werk von Clavijero, Francisco Javier: Storia Antica del Messico. 4 Bde. Cesena: Gregorio Biasani 1780. Vgl. hierzu allgemein auch Ette, Ottmar: Archeologies of Globalization. European Reflections on Two Phases of Accelerated Globalization in Cornelius de Pauw, Georg Forster, GuillaumeThomas Raynal and Alexander von Humboldt. In: Culture \& History Digital Journal (Madrid) I, 1 (June 2012) <http://dx.doi.org/10.3989/chdj.2012.003> (20 pp.). 
nössischen europäischen Wissenschaft zum inferioren Anderen Europas abgestempelt zu werden. Jenseits ihrer Fülle aber erscheint die Tropenwelt Amerikas in den Augen der meisten europäischen Philosophen als eine Falle, die ganz im Zeichen ihrer behaupteten grundlegenden Inferiorität eine von der ,eigenen` grundsätzlich geschiedene ,andere‘ Welt konfiguriert. Dass in dieser ,anderen Welt' auch ,anders' und auf Augenhöhe gedacht wurde, kam dabei nicht in Betracht: Die großen Autoren der europäischen Aufklärung konnten sich in der überwiegenden Mehrzahl kaum vorstellen, dass es in den Amerikas Philosophen geben könnte.

Vor diesem Hintergrund verweist die Beschreibung der am 10. November 1763 erfolgten Querung des Äquators im Journal historique von Antoine-Joseph Pernety bereits voraus auf grundsätzliche Auseinandersetzungen, die im Verlauf der wenige Jahre nach dieser Reise ausgebrochenen Berliner Debatte um die Neue Welt geführt werden sollten. Denn gerade die These von der fundamentalen Schwäche und Unterlegenheit der Neuen Welt hatte in der europäischen Aufklärungsliteratur Bilder erzeugt, die in den 1768 und 1769 in Berlin erschienenen Recherches philosophiques sur les Américains ${ }^{31}$ des Cornelius de Pauw im Zeichen der Degenerationsthese die Stufe einer teilweise geradezu apokalyptischen Bilderwelt erreichten. Wir haben uns im Zusammenhang mit den Berliner Verhältnissen und insbesondere mit der Oper Montezuma von Friedrich dem Großen bereits ausführlich mit dem holländischen „philosophe“ auseinandergesetzt. Unser Augenmerk haben wir in diesem Kapitel bislang stärker auf seinen Gegenspieler Antoine-Joseph Pernety gerichtet. Daher möchte ich im Folgenden nur noch einige wenige Aspekte der de Pauw'schen Philosophischen Untersuchungen über die Amerikaner in Erinnerung rufen.

Die Inferiorität einer noch nicht so alten ,Neuen Welt' war für de Pauw offenkundig, betraf alle Bereiche des natürlichen wie des kulturellen und zivilisatorischen Lebens, schloss aber auch eine Reihe von Gefahren und Gefährdungen mit ein, vor denen er seine europäischen Zeitgenossen $\mathrm{zu}$ warnen versuchte. Für den 1739 in Amsterdam geborenen und 1799 in Xanten verstorbenen Kleriker de Pauw war es schließlich evident, dass sich von den Tropen ausgehend Krankheiten und Epidemien wie Syphilis oder Gelbfieber über den gesamten Erdball ausbreiten würden und das menschliche Leben auf dem Planeten in seinem Fortbestand gefährden mussten. Er hatte begriffen, dass seine Zeit die Zeit

31 Vgl. Pauw, Cornelius de: Recherches philosophiques sur les Américains, ou Mémoires intéressants pour servir à l'Histoire de l'Espèce humaine. 2 Bde. Berlin: Chez Georges Jacques Decker, Imp. du Roi 1768-1769. 
eines erheblich intensivierten Austausches war, eine Zeit, in der jener Prozess de longue durée, den wir heute ,die“ Globalisierung nennen, wieder erheblich an Fahrt aufgenommen hatte. Was also konnten die Europäer in einer solchen Phase ihrer Geschichte gegen die Ausbreitung derartiger (fälschlich Amerika zugeschriebener) Krankheiten tun? Der durch seine Reise in die Neue Welt hervorgetretene Antoine-Joseph Pernety entwickelte in seiner Rede vom 7. September 1769 vor jener Berliner Académie des Sciences \& Belles-Lettres, deren Mitglied er war, auch eine dezidierte Gegenposition gegen Cornelius de Pauw. Doch zeigte sich gleichwohl, dass in dieser Berliner Debatte über die Neue Welt, die weit über die Grenzen Preußens und Europas hinaus wahrgenommen wurde, die Position de Pauws obsiegte. Es handelt sich dabei um eine Position, in der die ,Neue Welt', die auch geologisch jünger als die Alte und folglich viel später erst aus den Wassern emporgestiegen sei, als Ort einer prinzipiellen, von Anfang an gegebenen Inferiorität stigmatisiert wurde. Warum waren die Thesen von de Pauw in Europa so erfolgreich? Neben den großen rhetorischen Fähigkeiten und der klugen Taktik, nicht einfach die Argumente seines Gegenüber in das Gegenteil zu verkehren, war es sicherlich auch die Tatsache, dass einer europäischen Öffentlichkeit die Thesen des in Xanten wirkenden Klerikers wesentlich genehmer waren, welche sich im Übrigen an die populären Aussagen eines Naturhistorikers wie Buffon anschlossen. Wie bereits zuvor betont, sah Cornelius de Pauw die Europäer als die Krönung des Menschengeschlechts an, während die Bewohner der Tropen völlig inferiorisiert, ja aus dem Menschengeschlecht geradezu ausgeschlossen wurden.

Bei Cornelius de Pauw meint Tropikalisierung unübersehbar Inferiorisierung - und zugleich eine Animalisierung, welche jene Debatte um die Grenze zwischen Mensch und Tier wiederaufnahm, die bereits in der ersten Phase beschleunigter Globalisierung zum Kernbestand der europäischen Diskussionen über den „Mundus Novus“ gehört hatte. Die wissenschaftlich im Verständnis des 18. Jahrhunderts legitimierten Äußerungen des Holländers spitzten Buffons Histoire naturelle zu, der selbst niemals in Amerika, dafür aber zweimal für einige Monate am preußischen Hof in Berlin und Potsdam geweilt hatte. Sie entwerfen einen Gegensatz zwischen den gemäßigten Zonen insbesondere Europas einerseits und den Tropen Afrikas, Asiens und Amerikas andererseits, den als ein Zeugnis des Eurozentrismus zu bezeichnen wohl eher ein Euphemismus wäre. Wie kaum ein anderer europäischer Autor des 18. Jahrhunderts verstand es der Verfasser der Recherches philosophiques sur les Américains, seine philosophischen Untersuchungen zur indigenen Bevölkerung Amerikas ebenso polemisch wie protorassistisch zuzuspitzen.

Die bewusste und gezielte Abwertung der Welt der Tropen wie ihrer Bewohner kam überdies zum für Europas Interessen richtigen Zeitpunkt. Denn de 
Pauw verfasste seine Bände just, als die ökonomische Ausplünderung der Tropen insbesondere von England und Frankreich aus auf einen neuen Höhepunkt geführt und ebenso transkontinental wie transareal - unterschiedlichste Kulturräume der Tropen miteinander verknüpfend - organisiert wurde. Längst bildeten die Tropen eine intern vernetzte, aber kolonialistisch von außen kontrollierte transareale Struktur, die von Europa aus als komplementärer Ergänzungsraum funktionalisiert und gezielt globalisiert wurde. Die Verwandlung der Tropen in planetarisch ausgeweitete, dependente Gebiete, die freilich noch immer an den Tropen der Verwandlung partizipierten, wurde in der zweiten Phase beschleunigter Globalisierung spektakulär abgeschlossen. Spätestens ab diesem Zeitpunkt begannen die Traurigen Tropen ${ }^{32}$ eines Claude Lévi-Strauss konkrete historische Gestalt anzunehmen.

Daran vermochte letztlich auch das Akademiemitglied Pernety nichts zu ändern. Gleich zu Beginn seiner am 7. September 1769 vor der Berliner Akademie vorgetragenen und im Folgejahr veröffentlichten Dissertation sur l'Amérique et les Américains, contre les Recherches philosophiques de Mr. de $P^{* * * 33}$ baute Antoine-Joseph Pernety eine Frontstellung gegen die Thesen de Pauws auf, deren Strategie wir bereits an ihrem Beginn leicht erkennen können:

Herr von P. hat soeben ein Werk unter dem Titel Philosophische Untersuchungen über die Amerikaner veröffentlicht. Er ist darin bemüht, die unvorteilhafteste Vorstellung von der Neuen Welt \& deren Bewohnern zu vermitteln. Der affirmative \& entschlossene Ton, mit dem er seine Fragen vorstellt und beantwortet; der Brustton der Sicherheit, mit dem er vom Boden \& den Anbauprodukten Amerikas, von der dortigen Temperatur, der körperlichen \& geistigen Beschaffenheit der dortigen Bewohner, von deren Sitten \& Gewohnheiten und schließlich von ihren Tieren spricht; all dies könnte uns glauben lassen, dass er in all diese Länder einer weit sich erstreckenden Erde gereist wäre; dass er recht lange mit allen dort wohnenden Völkern zusammengelebt hätte. Man wäre versucht zu vermuten, dass unter den Reisenden, die dort lange Aufenthalte machten, die einen uns nur Märchen erzählt und die Wahrheit mit zahlreichen Dummheiten verkleidet hätten, oder aber die Wahrheit aus Schläue und Berechnung vergewaltigten. ${ }^{34}$

32 Vgl. Lévi-Strauss, Claude: Tristes Tropiques. Paris: Librairie Plon 1955.

33 Vgl. hierzu auch Gerbi, Antonello: La Disputa del Nuovo Mondo, S. 120-125.

34 Ich zitiere nach der von Cornelius de Pauw in den dritten Band seiner 1770 erschienen dreibändigen Ausgabe der Recherches philosophiques aufgenommenen Fassung; vgl. Pernety, Antoine-Joseph: Dissertation sur l'Amérique et les Naturels de cette partie du Monde. In: Pauw, Cornelius de: Recherches philosophiques sur les Américains, ou Mémoires intéressants pour servir à l'Histoire de l'Espèce humaine par Mr. de P. Nouvelle Edition, augmentée d'une Dissertation critique par Dom Pernety; \& de la Défense de l'Auteur des Recherches contre cette Dissertation. 3 Bde. Berlin: Decker 1770, Bd. 3, S. 7 f. 
Dom Pernety legte - wie bereits dargestellt - im selben Jahr 1769 ebenfalls in Berlin und in französischer Sprache seinen zweibändigen Reisebericht vor. Er spielte hier von Beginn an die Karte dessen aus, der als Augenzeuge jene Länder bereiste, die sein Widersacher Cornelius de Pauw ungeachtet des Grundtons größter Selbstsicherheit, mit der er nicht zuletzt auch die Berichte von Reisenden in der Tat einer pauschalen Kritik unterwarf, niemals selbst zu Gesicht bekommen hatte. Es handelt sich um die Trumpfkarte des Reisenden gegenüber den Beschränkungen des Daheimgebliebenen.

Dementsprechend stellte sich Pernety selbst - der als Akademiemitglied zurecht auf eine positive Aufnahme seiner Überlegungen durch die Berliner Akademie hoffen durfte - als weitgereisten Philosophen in den ihm sicherlich bekannten Zusammenhang jener Forderung nach einem „philosophe voyageur", welche Rousseau in seinem Discours sur l'origine et les fondements de l'inégalité parmi les hommes erhoben hatte. Daher betonte er bereits auf den ersten Zeilen seiner „Préface“, dass er sich der Welt Amerikas nicht allein als Leser angenähert habe: „J'avois lu \& relu quantité de rélations de l'Amérique; j'avois vu de mes propres yeux la plupart des choses, qui y sont rapportées.“35 Pernety präsentiert sich mithin als einen der Wahrheit verpflichteten Augenzeugen, der die Dinge selbst gesehen habe, von denen er berichtet. Und es habe ihn sehr erstaunt, all die Dinge, die er mit eigenen Augen gesehen habe, verworfen oder verkleidet zu sehen: ,voir contredites, ou travesties par Mr. de P.“ ${ }^{36}$ Wie bei Rousseau sind auch bei Pernety das eigene Sehen und damit der Gesichtssinn des reisenden Philosophen von entscheidender Bedeutung für eine fundierte Beurteilung sowie für die Glaubwürdigkeit eines Reisenden, welcher nur der wissenschaftlichen Wahrheit verpflichtet ist.

Auch an anderen Stellen dieser vor der Berliner Akademie vorgestellten Dissertation lässt sich unschwer erkennen, dass die Gedankenwelt Rousseaus in den Argumentationen Pernetys eine nicht zu unterschätzende Rolle spielt. So kehrt Pernety de Pauws Bild von den schwachen, geistig wie körperlich unterlegenen und unmännlichen (da bartlosen) Indianern um in ein genau gegenläufiges Bild. Denn die indigene Bevölkerung besitze „une santé ferme, vigoureuse, une vie qui passe ordinairement les bornes de la nôtre“ “. ${ }^{37}$ Die Indianer seien robust und stark, führten sie doch ein Leben in der Natur, das eine solche Konstitution begünstige. Dem starken, langlebigen Naturmenschen eigne aber auch ein wacher Geist: „un esprit sain, instruit, éclairé \& guidé par une philosophie vrai-

35 Ebda., S. $4 \mathrm{f}$.

36 Ebda., S. 5.

37 Ebda., S. 114. 
ment naturelle, \& non subordonnée comme la nôtre, aux préjugés de l'éducation; une âme noble, courageuse, un cœur généreux, obligeant: que faut-il donc de plus à Mr. de P. pour être véritablement hommes?" 38 Denn wer inmitten der Natur lebe, der sei auch geistig aufgeweckt und pflege eine Naturphilosophie, die sich nicht den Vorurteilen einer europäischen Erziehung unterordne. Die indigene amerikanische Bevölkerung sei daher von edler Seelengröße.

Die Gedankenwelt Antoine-Joseph Pernetys ist unzweifelhaft von JeanJacques Rousseau und dessen Vorstellung vom „natürlichen Menschen“ geprägt. Die Diskussion des Mensch-Tier-Gegensatzes nutzt Pernety geschickt, um neben der schon früh in seinen Text eingefügten und oft wiederholten Erwähnung amerikanischer Hochkulturen wie der Inkas zugleich seine Gegen-These von der Superiorität des „Homme naturel“, also der Urbevölkerung Amerikas, gegen de Pauw in Stellung zu bringen. Die Vertreter einer „philosophie vraiment naturelle“ dürfe man aber auch keinesfalls als Wilde, als „sauvages“, bezeichnen, müssten sich doch eher die Europäer ein derartiges Etikett gefallen lassen: „puisqu'en effet nos actions sont contraires à l'humanité, ou du moins à la sagesse qui devroit être le guide des hommes, qui se piquent d'être plus éclairés qu'eux.“" ${ }^{39}$ Denn stünden die Handlungen der Europäer nicht in offenkundigem Widerspruch zu den Interessen des gesamten Menschengeschlechts?

Dies waren fraglos Thesen und Themen, die man in Europa nicht einfach mit offenen Ohren hören und mit offenen Armen begrüßen mochte. Ich glaube nicht, dass sich in diesem Zusammenhang - etwa hinsichtlich der historischen Frage der Klimaentwicklung heute - an diesem Sachverhalt viel geändert hätte. Mokiert sich hier Pernety über die von seinem Gegner in der Berliner Debatte vorgetragene „Belle leçon dictée par les lumières de la pure raison“, ${ }^{40}$ so beklagt er im gleichen Atemzug das Unglück und die Unruhe eines Teils des Menschengeschlechts, das sich über alle anderen Teile erhaben glaube. Pernety sieht sich auf der Seite der universalen Vernunft, deren Walten er voranzubringen hoffte. Auch er sah die Neue Welt und deren indigene Bevölkerung als absolute Alterität, doch erblickte er dieses Andere nicht im Lichte einer Inferiorität, sondern vielmehr einer zumindest moralischen und philosophischen Superiorität: der des „Homme naturel“, des natürlichen Menschen, gegenüber dem durch einen langen zivilisatorischen Prozess degenerierten.

38 Ebda., S. $114 \mathrm{f}$.

39 Ebda., S. 115.

40 Ebda. 
Die Gesellschaft derer, die man als ,Wilde‘ bezeichne, sei folglich eine Gemeinschaft, die auf einem „contrat social“, auf einem Gesellschaftsvertrag im Sinne Rousseaus gründe:

Ich gestehe, dass wir die einen für die anderen gemacht sind \& dass aus dieser wechselseitigen Abhängigkeit der ganze Vorteil der Gesellschaft erwächst. Doch die erste Absicht dieser Vereinigung oder dieses Gesellschaftsvertrages; bestand darin, alle Vertragspartner darauf zu verpflichten, sich gegenseitig Hilfe zuzusichern \& sich nicht von einer Seite usurpieren zu lassen; ja sie sogar in ihren Usurpationen zu bestärken \& die andere Seite gänzlich im Mangel zu belassen. ${ }^{41}$

Dank einer derartigen Argumentation wird deutlich, dass Antoine-Joseph Pernety der vernichtenden Einschätzung der indigenen Bevölkerung durch Cornelius de Pauw nicht nur den starken Naturmenschen und Naturphilosophen auf der individuellen Ebene, sondern auch den Menschen der Gemeinschaft, den Menschen des „contrat social“, auf der kollektiven Ebene geradezu idealtypisch und in jedem Falle idealisierend - gegenüberstellt. Aus seiner Sicht kommt es darauf an, über den von ihm beschriebenen Gesellschaftsvertrag eine Gemeinschaft zu entfalten, die im Zeichen des Zusammenlebens stehen sollte. ${ }^{42}$

Eine solche Konvivenz auf der Grundlage eines Gesellschaftsvertrages, eines „contrat social“, schien nur wenigen Europäern eine verlässliche Grundlage für ein gedeihliches Zusammenleben zu sein: Waren denn die Indianer überhaupt auf der Höhe der Europäer, um mit diesen Verträge schließen zu können? So konnte Pernetys Argumentation nicht leicht bei seiner europäischen Leserschaft verfangen. Man darf hierin sehr wohl eine Schwäche der Argumentationsstrategie Pernetys erkennen, stellt er überdies den negativ eingefärbten Bildern de Pauws doch einfach - wie schon angemerkt - allzu oft positiv eingefärbte Gegen-Bilder entgegen. Diese gleichsam inverse Darstellung macht seine eigene Argumentation abhängig von jener seines Gegners, da sich Pernety immer wieder darauf beschränkt, die negativen Vorzeichen in der Darstellung des Cornelius de Pauw auf allen Ebenen in positive zu verwandeln. Darunter aber leidet die Eigenständigkeit seiner Beobachtungen wie die Originalität und Beweglichkeit seiner Dissertation, die zeitweise zum reinen Gegen-Diskurs verkommt. Eine solche Argumentationsstrategie machte es seinem Gegner leicht, die Oberhand zu behalten, ja sogar die Dissertation seines Gegners eigens abzudrucken, um noch deutlicher als Sieger aus dieser Debatte hervorzugehen.

41 Ebda., S. $115 \mathrm{f}$.

42 Vgl. zu dieser für die Literatur (und für die Literaturwissenschaft) zentralen Frage Ette, Ottmar: ZusammenLebensWissen. List, Last und Lust literarischer Konvivenz im globalen Maßstab (ÜberLebenswissen III). Berlin: Kulturverlag Kadmos 2010. 
Die Argumentationslinie, das genaue Gegenteil dessen zu behaupten, was de Pauw in seinen Recherches philosophiques sur les Américains vorstellte, prägt auch die „Seconde Partie“ der Pernety“schen Akademierede, die sich schon auf den ersten Zeilen von dem abwendet, was man „Herrn de P. zufolge glauben müsste“. ${ }^{43}$ Denn dieser Teil der Erde sei weltweit der beste, das Land sei äußerst fruchtbar, die Bäume überladen mit Früchten, wie er selbst im Garten des Gouverneurs von Montevideo mit eigenen Augen gesehen habe. ${ }^{44}$ Überhaupt könne man diesen wunderbaren Erdteil am besten mit dem Irdischen Paradies ${ }^{45}$ und mit den Gärten des Goldenen Zeitalters vergleichen: eine Welt der Wunder und einer Fülle, wie sie einst ein Vergil besungen habe. ${ }^{46}$ Pernety griff damit nicht nur auf die Suche des Christoph Kolumbus nach dem Irdischen Paradies in den Tropen Amerikas zurück, sondern tief in den abendländischen Fundus der griechisch-römischen Antike.

Umgekehrt versuchte er, die sich auf Buffon berufenden Argumente seines Widersachers dadurch zu entkräften, dass er diesen seine eigene Erfahrung, seine eigene Augenzeugenschaft entgegenstellte. Würde man de Pauw folgen, so müsste man die amerikanische Hemisphäre als eine „terre maudite“, als eine verfluchte Erde begreifen; ${ }^{47}$ in Wirklichkeit aber habe sich Pernety selbst davon überzeugen können, dass in Amerika „le principe de vie“, folglich das Lebensprinzip und wohl auch die Lebenskraft, wesentlich stärker ausgeprägt sei als in Europa. ${ }^{48}$ Nichts von dem, was de Pauw in seinen Recherches philosophiques behauptet, bleibt in Pernetys Gegen-Diskurs bestehen. Aber war dies eine intelligente Diskursstrategie?

Zweifellos war es ebenso zutreffend wie klug, gegen die einseitigen Anschuldigungen de Pauws, der amerikanische Kontinent habe den Rest der Welt mit Epidemien und Krankheiten - allen voran der Syphilis - überzogen, mit guten Gründen auf eine wechselseitige Globalisierung von Krankheiten aufmerksam zu machen, wie sie in der Tat mit der ersten Phase beschleunigter Globalisierung einhergegangen war. Die Bewohner Amerikas würden keineswegs von unendlich vielen und schrecklichen Krankheiten gepeinigt, sondern seien vielmehr als überaus gesund und robust anzusehen:

43 Pernety, Antoine-Joseph: Dissertation sur l'Amérique et les Naturels de cette partie du Monde, S. 32.

44 Ebda.

45 Ebda., S. 35.

46 Ebda., S. 36.

47 Ebda., S. 43.

48 Ebda., S. 42. 
Sei es durch körperliche Ertüchtigung oder sei es durch die Konstitution ihres Temperaments sind sie höchst gesund, sie sind frei von Lähmungen, von Wassersucht, von Gicht, von Atemnot, von Asthma, von Steinen aller Art; dies sind Krankheiten, mit denen die Natur, die diesem Kontinent so viel gegeben hat, uns nochmals begünstigen wollte. Sie hatte freilich die Rippenfellentzündung Canada gelassen; \& wir haben ihr die kleinen Pocken (small pocks) gebracht. Die Amerikaner haben uns die ihrigen mit dem Rechte des Austausches \& des Handels übertragen. ${ }^{49}$

Während Europa bei Pernety zum Kontinent der Gebrechlichen wird, die unter allen möglichen Krankheiten leiden, gerät dem Franzosen Amerika zum Inbegriff einer körperlichen Gesundheit, die allenthalben sichtbar sei. Nicht umsonst griffen auch spätere Verteidiger der Sache Amerikas und der dortigen Bevölkerungen gerne auf die Argumente Pernetys zurück, indem sie die Degenerierung der europäischen Bevölkerung im ,alten Europa' hervorhoben. Wir werden mit dem neuspanischen Dominikanermönch Fray Servando Teresa de Mier noch eine dieser Stimmen näher kennenlernen.

Gegen die gewiss nicht nur von de Pauw vertretene These von der Degenerierung des Menschengeschlechts in den Tropen der Neuen Welt setzt Pernety eine hemisphärische Konstruktion, die den amerikanischen (das heißt indigenen) Menschen vom hohen Norden bis zum tiefen Süden unter Verweis auf die unterschiedlichsten Reisenden in das glanzvollste Licht rückt:

\footnotetext{
Wenn wir vom Norden bis zum äußersten südlichen Rand des Neuen Kontinents fortschreiten, so stellen alle Völker, auf die wir auf unserem Wege stoßen, gut gebaute Menschen dar. Denn so sind, wenn wir Vincent le Blanc \& den anderen Reisenden glauben, die Mexikaner, die Brasilianer, die Peruaner, jene aus Paraguay, aus Chile \& schließlich die Patagonier. ${ }^{50}$
}

Das Urteil des französischen Reisenden umfasst trotz aller ethnischen Verschiedenheit, die Pernety vielleicht nicht gänzlich bewusst gewesen sein dürfte, alle so unterschiedlichen indigenen Völker - gleichviel, ob sie in tropischen Tiefländern oder in den Außertropen, ob sie in hochandinen Regionen oder in Küstenbereichen siedelten. Alle seien sie weit davon entfernt, im Sinne de Pauws degeneriert zu sein, sondern würden durch ihre Robustheit und ihre eiserne Gesundheit gegenüber den unter allerlei Krankheiten leidenden Europäern höchst positiv hervorstechen. Für Antoine-Joseph Pernety musste der „Homme naturel“" natürlich stark sein.

Doch Pernetys Lob der indigenen Bevölkerung beschränkte sich nicht auf deren bloßen stattlichen Körperbau. Vielmehr führte er auch zahlreiche Ele-

49 Ebda., S. 48.

50 Ebda., S. 49 f. 
mente ihrer Kultur an, die den französischen Reisenden beeindruckt hätten und die Thesen eines Cornelius de Pauw glatt widerlegten. Dabei zeichneten sich nicht nur einzelne Völker, sondern alle Amerikaner ebenso durch eine den Europäern gegenüber weit größere und ehrlichere Gastfreundschaft aus, ja legten Tugenden an den Tag, die man zu bewundern nicht umhin könne:

Ohne dass sie einen Lykurg als Gesetzgeber gehabt hätten, respektieren die Kariben \& im Allgemeinen alle amerikanischen Völker ihre Greise unendlich, hören ihnen aufmerksam $\mathrm{zu}$, verweisen auf die Gefühle der Alten \& verhalten sich nach ihrem Willen. Sie sind auf natürliche Weise frank und frei, wahrheitsliebend \& haben zu allen Zeiten Zeichen von Offenherzigkeit, von Höflichkeit, von Freundschaft, von Großzügigkeit \& von Dankbarkeit gegeben. Diejenigen, die lange mit ihnen in Beziehung standen, schreiben ihnen mehr Gerechtigkeit zu als Herr von P. Wenn man heute bei ihnen die Lüge, die Perfidie, den Verrat, die Freizügigkeit \& mehrere andere Laster findet, dann muss man sich an die schädlichen Beispiele der Europäer \& an die schlechten Behandlungen halten, welche diese an ihnen verübten. Auf jeder Seite der Berichte sieht man, wieviel diese vom Alten Kontinent in der Neuen bewirkten einschließlich der Kunst, die sie so gut beherrschen, auf gemeine Weise zu täuschen. ${ }^{51}$

Antoine-Joseph Pernety ist bereit, alle Übel und Missetaten der Alten Welt und alle moralische Größe der Neuen Welt zuzuschlagen. Daher zögert er auch nicht, Lüge und Betrug dort, wo sie in Amerika überhaupt vorkämen, auf den schädlichen Einfluss der Europäer zurückzuführen. Von Natur aus seien die indigenen Völker Amerikas aber moralisch wie charakterlich gut und seien die Repräsentanten einer Welt, die der Perfidie der Europäer unterlegen sei. Auch an diesen Stellen, wo es im Grunde um den „Homme naturel“ geht, ist der Einfluss von Rousseau auf das Denken Pernetys unübersehbar, seien es doch die pervertierten Gesellschaften Europas, die den moralischen Verfall der Naturvölker in der Neuen Welt zu verantworten hätten.

Angesichts eines derartigen Sittengemäldes, das in einem scharfen Kontrast den robusten und guten Naturmenschen vom nicht nur verdorbenen, sondern weit mehr noch die anderen Völker verderbenden Europäer absetzt, verwundert es nicht, dass Pernety die Bewohner Amerikas auch zu den glücklicheren Menschen erklärt. ${ }^{52}$ Denn sie lebten noch im Einklang mit der Natur: Wie könnten sie da nicht glücklicher sein als die von einem langen zivilisatorischen Prozess zu Grunde gerichteten Europäer? Die wenig nuancierende Argumentationsstrategie Pernetys, die es alleine darauf anlegt, de Pauws Behauptungen durch Gegen-Behauptungen zu widerlegen, affiziert letztlich weite Teile der Dissertation, die sich in diesen langen Passagen weder empirisch noch epistemologisch den Aus-

51 Ebda., S. 81-83.

52 Ebda., S. 87. 
führungen de Pauws als überlegen erweist. Pernetys Sichtweise der Amerikaner ist in einem hohen Maße ebenfalls bestimmten Positionen der europäischen Aufklärung verpflichtet, ganz wie dies bei de Pauw der Fall war: Nur sind seine Vorbilder deutlich auf der Seite Rousseaus zu finden. Auch wenn er als Reisender anders als der holländische Philosoph Teile Amerikas aus eigener Anschauung kannte, so wurzeln die Voraussetzungen seines Blicks auf die Neue Welt doch nicht weniger in Vorstellungen, die in Europa während des Aufklärungszeitalters entwickelt wurden.

Mit der von Pernety immer wieder vorgetragenen Frage nach den Patagoniern greift das Mitglied der Berliner Akademie eine Problematik auf, die auch Jean-Jacques Rousseau nicht von ungefähr erwähnt hatte („sans oublier les Patagons vrais ou faux“"53). Zweieinhalb Jahrhunderte nach Pigafettas ersten Berichten von Riesen in Patagonien wollte er die noch immer ungelöste Frage endlich einer wissenschaftlichen Erforschung und abschließenden Bewertung zuführen. Diese Frage war insofern von großer epistemologischer Bedeutung, als das bestätigte Vorkommen von Riesenmenschen unverkennbar gegen die noch immer gültige These Buffons gestanden hätte, dass alles in Amerika, in Flora und Fauna, in allen Bereichen von Natur und Kultur, kleiner und schwächlicher sei als in der Alten Welt. Noch ein Hegel wird im 19. Jahrhundert in seinen Vorlesungen zum Ärger Humboldts davon faseln, die Krokodile oder Alligatoren Amerikas seien so viel schwächer als deren Vertreter in der Alten Welt, verglichen etwa mit ihren Artgenossen am Nil.

Nicht umsonst hatte Pernety seinem Reisebericht eine Relation sur les Patagons beigefügt, die er publikumswirksam bereits in den Titel seines Journal historique aufnahm - und hatte nicht Pierre Moreau de Maupertuis, der Präsident der Berliner Akademie, zu den riesenhaften Patagoniern verlauten lassen, dass man vernünftigerweise nicht mehr an ihrer Existenz zweifeln könne ${ }^{54}$ Es dürfte kaum überraschen, dass er de Pauws Behauptung, bei der Rede von den Menschen mit riesenhaftem Wuchs in Patagonien handele es sich um von europäischen Reisenden erflunkerte Fabelwesen, nicht nur die teilweise Manipulation von Quellen vorwarf, ${ }^{55}$ sondern in ganz grundsätzlicher Manier entgegentrat: „Ich begreife nicht, wie Herr von P. es unternehmen konnte, die Existenz von riesenhaften Patagoniern auszulöschen. Räsoniert man seiner philosophischen

53 Rousseau, Jean-Jacques: Discours sur l'origine et les fondements de l'inégalité parmi les hommes, S. 213.

54 Vgl. hierzu Moureau, François: L’Amérique n’a aucun avenir: les idées ,philosophiques‘ de Cornelius De Pauw. In: Travaux de Littérature (Genf) 24 (2011), S. 66.

55 Pernety, Antoine-Joseph: Dissertation sur l'Amérique et les Naturels de cette partie du Monde, S. 68. 
Methode folgend, so wäre nichts fähig, in seinen Augen durch deren Existenz die Degradation \& Degenerierung der Menschenrasse in Amerika zu belegen." ${ }^{56}$ Es ging folglich um nicht mehr und nicht weniger als um die Einschätzung des zivilisatorischen Prozesses der Menschheit im Sinne einer ständigen Degenerierung und eines ständigen Abstiegs oder im Sinne eines Vorgangs, der das Menschengeschlecht aus tiefster Barbarei herausgeführt hätte. Pernety dies war offenkundig - neigte der ersten, von Rousseau vertretenen These zu; de Pauw vertrat in seinen Recherches philosophiques sur les Américains offensiv die zweite.

Doch gerade an dieser Stelle wird deutlich, wie sehr Pernety mit seinem nicht selten sehr mechanisch wirkenden Bemühen, de Pauw in allen Punkten zu widerlegen, über sein Ziel hinaus schoss und die Legitimität und Autorität seines eigenen Diskurses beschädigte. Er war in den Augen seiner Zeitgenossen keineswegs glaubwürdiger, nur weil er selbst auch für eine nicht allzu lange Zeit in die amerikanischen Tropen gesegelt war. De Pauw schätzte diesen Sachverhalt richtig ein und wusste, dass allein eine gewisse Augenzeugenschaft seinem Kontrahenten noch lange keine stärkere Position verschaffen konnte. All dies dürfte entscheidend zu dem unbestreitbaren Faktum beigetragen haben, dass sich die von Pernety inkriminierte „méthode philosophique“ des Cornelius de Pauw in der Berliner Debatte, also in jener zunächst von Berlin ausgehenden europäischen Phase des Disputs um die Neue Welt, letztlich durchzusetzen vermochte und für lange Zeit die Oberhand behielt. Um über die Neue Welt glaubwürdig zu berichten, musste man nicht vor Ort gewesen sein - eine epistemisch fundamentale Position, der selbstverständlich ein Diderot ebenso wie ein Voltaire, ein Raynal ebenso wie ein Kant zuzurechnen waren. Erst am Ausgang des 18. Jahrhunderts sollte sich auf diesem Gebiet, wie wir noch sehen werden, eine gewisse ,Revolution' ereignen.

Worin aber bestand die ,Methode“ des Cornelius de Pauw, die - wie bereits gezeigt wurde - als solche von dem neuspanischen Jesuiten Francisco Javier Clavijero inkriminiert worden war? Denn hatte sich letzterer über sie nicht aus amerikanischer Sicht lustig gemacht und sich auf einen afrikanischen Philosophen wie Anton Wilhelm Amo bezogen, um eben diese ,Methode“ auf Europa und dessen Bewohner anzuwenden? Und welche Folgen hatte sie für ein Verständnis der unterschiedlichsten Phänomene der Globalisierung aus einer europäischen Perspektive im Zeitraum vor jenem Alexander von Humboldt, der

56 Ebda., S. 51: „Je ne conçois pas comment Mr. de P. a entrepris d'anéantir l'existence des Patagons Géants. En raisonnant suivant sa méthode philosophique, rien n'étoit plus capable que cette existence, de prouver à ses yeux, la dégradation \& la dégénération de la race humaine en Amérique.“ 
genau eine Woche nach der Rede Pernetys vor der Berliner Akademie nach eigenem Bekunden im Zeichen eines Kometen in der preußischen Hauptstadt das Licht der Alten Welt erblickte?

Zweifellos war Cornelius de Pauw ein Denker der Globalität und sein Werk eine findige und zeitgemäße Antwort auf jene zweite Phase beschleunigter Globalisierung, ${ }^{57}$ welche die zweite Hälfte des 18. Jahrhunderts bis deutlich über die Jahrhundertwende hinaus umfasst. Einheit und Aufteilung des Planeten stellen Problematiken dar, die de Pauws gesamtes Werk über die Alte wie die Neue Welt durchziehen und um die sein Denken auch mit Blick auf seine Werke über die Chinesen wie die Ägypter kreist. Dabei begreift der Autor der Recherches philosophiques sur les Américains ganz im Sinne der Naturgeschichte Buffons diese ,Neue' Welt als eine auch geologisch wie geomorphologisch jüngere, neuere Welt, in der es überall von Sümpfen wimmele. ${ }^{58}$ Wir hatten gesehen, dass man sich in der ersten Hälfte des 18. Jahrhunderts den Kopf über die genaue Form der Erde zerbrach und Expeditionen dazu ausrüstete, die von Isaac Newton vertretene These von der Abplattung der Pole wissenschaftlich und empirisch $\mathrm{zu}$ überprüfen.

In der zweiten Hälfte des 18. Jahrhunderts ging es im Zeichen einer anhebenden Beschleunigung der Globalisierung weit mehr um die Frage, wie sich die beiden Hemisphären, wie sich die ,Alte‘ und die ,Neue‘ Welt zueinander verhalten. So bildet für de Pauw wie für viele seiner Zeitgenossen - immerhin handelte es sich um die vorherrschende Lehrmeinung in den zuständigen Wissenschaften! der gesamte Planet eine Einheit, jene ,Maschine des Globus', die sich freilich naturhistorisch gesehen gleichzeitig in erdgeschichtlicher Ungleichzeitigkeit befindet. Daran, dass unser Planet eine Einheit bildet, war nicht zu zweifeln; dass diese Einheit jedoch in zwei ungleiche Hälften zerfiel, war in vielen europäischen Wissenschaften State of the Art. Denn während es in der Alten Welt längst zu einer gewissen Beruhigung (,repos“) gekommen sei, brodele und schüttele es in den Gebirgen der Neuen Welt, wo sich die Landmassen sich erst wesentlich später aus dem Wasser gehoben hätten. Und dieser Prozess sei noch lange nicht abgeschlossen. ,Alt' steht ,neu' auch geologisch gegenüber - und das ,Alte' ist dem ,Neuen` überlegen! Noch bei Hegel werden Sie - wie ich bereits anmerkte - auf derartige Formulierungen noch in seinen Berliner Vorlesungen immer wieder stoßen.

57 Vgl. hierzu ausführlicher Ette, Ottmar: Weltbewußtsein. Alexander von Humboldt und das unvollendete Projekt einer anderen Moderne. Weilerswist: Velbrück Wissenschaft 2002, S. 2527; sowie (ders.): TransArea - eine literarische Globalisierungsgeschichte, S. 14-18.

58 Vgl. hierzu Pauw, Cornelius de: Recherches philosophiques sur les Américains, ou Mémoires intéressants pour servir à l'Histoire de l'Espèce humaine, Bd. 1, S. 102. 
Doch diese zweigeteilte Welt ist eins - und beide Hemisphären, so wird rasch deutlich, sind fortan unauflöslich miteinander verwoben und aneinander gekettet. Cornelius de Pauw erweist sich gleich zu Beginn seines Werkes als ein Denker der Globalität, genauer: als Denker einer Globalität, die von einer scharf asymmetrischen Struktur geprägt ist. Diese Asymmetrie brachte es mit sich, dass das alte Amerika, „l'ancienne Amérique“, das noch die Zeitgenossen der Conquista kannten, nicht mehr besteht, ist es doch „entièrement bouleversé par la cruauté, l'avarice, l'insaciabilité des Européens“. ${ }^{59}$ Deklamatorisch prangert de Pauw die Unersättlichkeit der europäischen Suche nach Reichtümern an. Aus den spanischen Konquistadoren sind Europäer geworden - und die von ihnen ausgehende zerstörerische Gewalt öffnet sich bei de Pauw sogleich auf mögliche Katastrophen von planetarischem Ausmaß. Eine selbstverschuldete Auslöschung des gesamten Menschengeschlechts wird plötzlich vorstellbar,

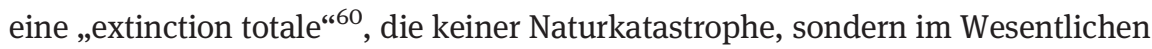
menschlichem Handeln geschuldet wäre. Die Zerstörung unseres Planeten: Mit de Pauw wird sie im 18. Jahrhundert konkret vorstellbar! Diese Vorstellung von der totalen Vernichtung unseres Habitats sollte seit der Aufklärung und der Sattelzeit der Moderne die gesamte Epoche einer europäischen Moderne begleiten. Denn vor dem Hintergrund der kolonialen Expansion des 15. und 16. Jahrhunderts warnt de Pauw vor den Konsequenzen jener zweiten, sich von Europa aus über den Globus ausbreitenden Expansionswelle, deren Zeitgenosse und Zuschauer der holländische Abbé selbst ist. Europa stehe im Begriff, unter der Anleitung von „politiques“ und unter dem Beifall mancher „philosophes“ die „Terres Australes“ machtpolitisch und wissenschaftlich in Besitz zu nehmen, ohne zu bedenken, wieviel Unglück man notwendig über die dort lebenden Völker bringen werde. $^{61}$

Die Maschine des Erdkörpers ist zwar für die europäische Aufklärung durchaus eine einzige, spaltet sich aber in zwei Hemisphären auf, die in ihrer Gegensätzlichkeit in manchen Köpfen bis in unsere Tage fortbestehen. Die Langzeitwirkung derartiger Bilder ist zumindest mit Blick auf das 19. Jahrhundert kaum zu überschätzen. Die Unterscheidung und Scheidung zweier Hemisphären bildet jedenfalls die grundsätzliche diskursive Setzung der Recherches philosophiques sur les Américains und ist zunächst zwar rationaler, aber nicht relationaler Natur. Auf diesen beiden Ebenen, jener der Zweiteilung der Erde wie der Nicht-Relationalität des Verhältnisses zwischen beiden Welten, sind die

59 Ebda., Bd. I, S. a4r.

60 Ebda., Bd. I, S. a3r.

61 Ebda. 
Unterschiede zwischen den Sichtweisen de Pauws und Pernetys im Grunde nicht sehr erheblich.

Dem fundamentalen Argumentationsschema einer Zweiteilung, ja mehr noch einer Gegensätzlichkeit der beiden Hemisphären folgen nicht allein die naturhistorischen, sondern auch die kulturhistorischen Überlegungen von de Pauws Recherches philosophiques. Dabei ließ Cornelius de Pauw keinerlei Zweifel daran aufkommen, dass für ihn die Entdeckung Amerikas durch Christoph Kolumbus jenes globalgeschichtliche Ereignis war, das aus seiner Sicht die Geschichte des Planeten am nachhaltigsten geprägt und gleichsam die naturhistorische Differenz zwischen Alter und Neuer Welt am stärksten hervorgetrieben und in den kulturgeschichtlichen Bereich deterministisch übersetzt hatte. ${ }^{62}$ Wir konnten bei unserer Analyse der Auseinandersetzungen zwischen dem Jesuitenschüler de Pauw und dem neuspanischen Jesuiten Clavijero bereits sehen, wie der in Amsterdam geborene Kleriker, der wohl auch an der für außereuropäische Fragen bestens ausgestatteten Göttinger Universität studiert hatte, ${ }^{63}$ in scharf konturierten Wendungen seines französischsprachigen Werkes eine Gegensätzlichkeit auf die Spitze trieb. Diese übertrug die Opposition von ,alter und ,neuer‘ Welt nun auf ,Europäer' und ,Amerikaner'. So sind die Menschen zwar Bewohner einer Welt, die schroffer zweigeteilt jedoch kaum vorstellbar sein könnte.

Zugleich wird in dieser Argumentations- und Diskursstruktur durchaus absichtsvoll Kultur in Natur verwandelt. Und mehr noch: Die Welt Amerikas wird in ein Reich der Natur (zurück-)verwandelt, während Europa im Zeichen einer erfolgreich vorrückenden Kultur und Zivilisation steht. Einem Reich der Zeichen steht ein Reich des Wissens und der Deutung dieser Zeichen gegenüber. Aus dieser (europäischen) Kultur aber wird die Neue Welt folgenreich exkludiert. Damit schuf de Pauw die Voraussetzungen für ein Rassedenken und einen später aufkeimenden Rassismus, der stets - wie Roland Barthes in seinen Mythologies darlegte - darauf zurückgreift, ein kulturelles Phänomen zu naturalisieren und damit als Natur erscheinen zu lassen.

An spektakulärer Inszenierung und überscharfer, dramatischer Beleuchtung ist de Pauws Argumentationsweise, die sich in ihrem weiteren Verlauf als ein gutes Beispiel für Rassismus avant la lettre begreifen ließe, kaum zu über-

62 Ebda., Bd. I, S. a2v f.

63 Vgl. hierzu Church, Henry Ward: Corneille de Pauw, and the controversy over his „Recherches philosophiques sur les Américains“. In: PMLA (New York) LI, 1 (March 1936), S. $180 \mathrm{f}$; sowie Beyerhaus, Gisbert: Abbé de Pauw und Friedrich der Große, eine Abrechnung mit Voltaire. In: Historische Zeitschrift (München - Berlin) 134 (1926), S. 465-493; sowie Moureau, François: L’Amérique n'a aucun avenir, S. 68. 
bieten. Dabei bilden die Recherches philosophiques sur les Américains ein Werk aus Worten, das sich auf keinen empirisch untersuchten Gegenstand, sondern ausschließlich auf andere Werke und Worte, auf andere Texte und intertextuelle Netzwerke bezieht. Wir haben hierzu im Kapitel über Cornelius de Pauw und Friedrich den Großen ausführlich gesprochen. ${ }^{64}$

Folglich steht das Werk de Pauws ein für eine Textwissenschaft im schwachen Sinne. Die Methode des Cornelius de Pauw, so ließe sich mithin sagen, war rein textbasiert: Sie ist in diesem Sinne eine philologische Methode. Mit guten Gründen könnte man daher die Recherches philosophiques als eine absichtsvolle und nicht enden wollende Reise durch die Welt der Texte charakterisieren. Ohne jegliche empirische Basis und ohne direkte Kenntnis der von ihm beschriebenen, diskutierten und bewerteten Gegenstände konsultierte de Pauw ebenso historische Chroniken wie zeitgenössische Reiseberichte, ebenso ihm zugängliche Bordbücher wie Manuskripte von Handelsreisenden, ebenso historiographische Werke des 16. Jahrhunderts wie philosophische Traktate des 18. Jahrhunderts. Und er tat dies stets, um seine eigenen vorgefassten Meinungen zu unterstützen, verwandte Intertextualität folglich rein diskursaffirmativ. Cornelius de Pauws ,Neue Welt‘ war eine Welt der Texte, auch wenn diese Welt keine Bibliothek (und schon gar keine Borgesianische „Bibliothek von Babel“) war.

Diese ,Neue Welt' wurde den rhetorischen Verfahren aufklärerischer Kritik ausgesetzt - und man kann an dieser Stelle unschwer die Schattenseite einer aufklärerischen Konzeption von Kritik erkennen. Dabei schenkte der sich zum damaligen Zeitpunkt in Potsdam und Berlin aufhaltende Holländer in aller Regel europäischen Stimmen weitaus mehr Glauben als Autoren, die - wie etwa Garcilaso de la Vega el Inca - amerikanischer Herkunft waren, französischen Verfassern weit mehr Vertrauen als spanischen usw. Es gab durchaus einige wenige amerikanische Stimmen in den Recherches, doch wurden diese absichtsvoll ebenso verworfen wie die Stimmen spanischer Kleriker, die vor den Augen dieses holländischen Jesuitenschülers keine Gnade fanden. Entscheidend für seinen kritischen Umgang mit den ihm zur Verfügung stehenden Texten aber war, dass es für de Pauw darauf ankam, einzelne Textbausteine zu finden, die für seine eigene, völlig unabhängig von empirischen Befunden getroffenen Einschätzungen amerikanischer Gegenstände nützlich und diskursstützend erschienen. Man darf getrost diese Vorgehensweise als die ,philosophische Methode' des Cornelius de Pauw bezeichnen.

64 Vgl. des weiteren Ette, Ottmar: Wörter - Mächte - Stämme. Cornelius de Pauw und der Disput um eine neue Welt. In: Messling, Markus / Ette, Ottmar (Hg.): Wort Macht Stamm. Rassismus und Determinismus in der Philologie (18. / 19. Jh.). Unter Mitarbeit von Philipp Krämer und Markus A. Lenz. München: Wilhelm Fink Verlag 2013, S. 107-135. 
De Pauws Verhältnis zur zeitgenössischen Wissenschaft offenbart uns aber noch andere Einsichten: Denn bei ihm zeichnet sich ein höchst aufschlussreiches Verständnis abendländischer Wissenschaft ab. Letztere ist niemals nur bloßes Instrument einer anderen, insbesondere einer politischen Macht, sondern stets auch eine Macht für sich und verfolgt eigene Interessen, bei deren Durchsetzung sie auch zerstörerische ,Nebeneffekte‘ einkalkuliert. Die Kritik des Klerikers an der europäischen Expansion wie an der europäischen Wissenschaft schloss freilich die Kritik an der eigenen Wissenschaft - an der de Pauw'schen Wissenschaftspraxis also - nicht mit ein. Denn diese Praxis seiner Wissenschaft verteidigte er bedingungslos.

An der Tatsache, dass de Pauw für seinen eigenen Ansatz im Allgemeinen und für seine philosophischen Recherches im Besonderen den Status des Wissenschaftlichen einforderte, kann keinerlei Zweifel bestehen. So hielt er in der nach der Veröffentlichung seines zweiten Bandes ausbrechenden Berliner Debatte um die Neue Welt seinem ärgsten Widersacher im dritten, bereits 1770 erschienenen Band seiner Recherches philosophiques sur les Américains entgegen, dieser habe weder die Wissenschaftlichkeit seines Ansatzes erkannt noch auf der Höhe seiner Wissenschaft argumentiert. ${ }^{65}$ Die sich gegen einen bloß ,parlierenden', ohne Methode und System vor sich hinschreibenden Gegner wendende Replik de Pauws fiel daher vernichtend aus:

Hört man ihn sprechen, so scheint es, als ob es ihm genügte, die Feder zu ergreifen, um in aller Form eine Ablehnung niederzuschreiben [...]. Er steuert daher keinerlei Bemerkung über die Naturgeschichte bei: Er liebte es mehr, über Moral zu schwafeln, Zusammenstellungen von diesem Zusammensteller Gueudeville zu übernehmen \& endlos zu räsonieren.

Wenn man ein Buch über eine Wissenschaft angreift, dann muss man sich der Argumente bedienen, die aus dieser Wissenschaft stammen, \& nicht aus einer anderen. ${ }^{66}$

De Pauw greift nicht allein die Argumente, sondern die gesamte Methode von Pernety an - und diese erscheint ihm als gänzlich unwissenschaftlich! Interessant an dieser Argumentationsweise ist, dass sich de Pauw nicht allein auf die im Zeichen Buffons stehende Wissenschaft der „Histoire naturelle“, sondern auch auf seine eigene philologische Vorgehensweise beruft. Letztere habe sich

65 Diese neue Ausgabe von 1770 wurde in den Folgejahren mehrfach auch an anderen Druckorten wieder aufgelegt.

66 Pauw, Cornelius de: Recherches philosophiques sur les Américains ou Mémoires intéressants pour servir à l'Histoire de l'Espèce Humaine. Par Mr. de P***. Avec une Dissertation sur l'Amérique \& les Américains, par Dom Pernety. Et la Défense de l'Auteur des Recherches contre cette Dissertation. Berlin: Chez Georges Jacques Decker 1770, Bd. 3, S. 11. 
- anders als die seines Widersachers - niemals unkritisch irgendwelcher Kompilationen bedient. Auch habe er sich nicht einfach über Moral ausgelassen und darüber eine wissenschaftliche Auseinandersetzung vergessen. De Pauw setzt sich damit auf das hohe Ross der zeitgenössischen Wissenschaft und reklamiert für sich eine Naturgeschichte und eine methodologisch abgesicherte Vorgehensweise, von der sein Kontrahent nichts wisse.

Diese scheinbar wissenschaftliche Argumentation entpuppt sich weniger für die Zeitgenossen, wohl aber für uns Heutige aus der zeitlichen Distanz als eine pseudo-wissenschaftliche. Denn diese ,philologisch-kritische‘ Arbeit am Text unterwirft der holländische „philosophe“ keinerlei eigener Kritik mehr. Er überprüft mithin auch nicht, welche weltweiten Folgen seine eigenen wissenschaftlichen Interessen - parallel zu den Interessen jener Wissenschaften, die sich auf Gegenstände der Natur (wie Temperatur und Territorium) richten - zeitigen könnten. Wie schwerwiegend diese Konsequenzen aber sein konnten, sollte der weitere Fortgang der von den Recherches philosophiques ausgelösten Debatte in aller Deutlichkeit vor Augen führen. Wir hatten bereits bei Clavijero deutlich gesehen, in welchem Maße die Argumente von de Pauw aus amerikanischer Sicht der Lächerlichkeit preisgegeben werden konnten. Das Problem freilich bestand darin, dass diese transatlantische Kritik in Europa kaum wahrgenommen wurde und sich daher erst ein europäischer Wissenschaftler finden musste, um diese Kritikpunkte in Europa selbst entsprechend stark zu machen. Denn noch für lange Zeit vertraute die europäische Wissenschaft allein sich selbst, folgten etwa in der Philosophie ein Kant oder ein Hegel, aber auch noch ein Marx oder Engels keinen ,außereuropäischen` Argumenten.

Dabei demonstrierte diese auf den ersten Blick lokale, periphere Berliner Debatte um die Neue Welt - aus dem heutigen Blickwinkel betrachtet - zugleich sehr deutlich, dass es unzureichend und grob fahrlässig ist, wenn man sich alleine auf die europäische Aufklärung konzentriert und verlässt. Denn allein von Europa aus ist selbst das Phänomen der Aufklärung nicht adäquat zu durchdringen und zu begreifen. Längst hatte die République des Lettres einen transarealen Zuschnitt: Was in Berlin diskutiert wurde, konnte und musste auch die Gemüter in Mexico-Stadt, in Philadelphia oder in Lima erhitzen. Vergessen wir also nicht, dass die Aufklärung im Zeichen der zweiten Phase beschleunigter Globalisierung - und dies heißt ab der Mitte des 18. Jahrhunderts - ein tendenziell weltweites, weltumspannendes Phänomen darstellt, das auch in seinen lokalen Entwicklungen translokale und damit letztlich transareale Dimensionen beinhaltet und entfaltet.

Die ersten Runden dieses von Berlin ausgehenden und in Berlin geführten Disputs gingen ohne Frage an Cornelius de Pauw. Denn dieser hatte geschickt nur auf die Chance eines Gegenangriffs, der im wesentlichen seine Abwertung 
der Amerikaner in ein idealisierendes Gegen-Bild alles Amerikanischen umzukehren suchte, gewartet und druckte großzügig Pernetys Attacke in seiner bereits erwähnten und noch 1770 wiederum in Berlin veröffentlichten dreibändigen Neuausgabe der Recherches philosophiques sur les Américains ab. Es handelt sich keineswegs um eine großzügige Geste gegenüber seinem Widersacher, sondern um wohlkalkulierte Berechnung in einer rasch sich erhitzenden Debatte, die weit über Berlin, Preußen und Europa hinaus ausstrahlte. Ihr fügte er eine vehemente Verteidigungsschrift seiner eigenen, vielfach weiter zugespitzten Thesen bei. Pernetys über weite Strecken inverse Darstellung der Thesen seines Kontrahenten konnte von diesem leicht diskursiv vereinnahmt werden.

Gewiss darf man bei Antoine-Joseph Pernety ,elements of a modern ethnological attitude“ 67 erkennen, zu denen man sicherlich „the critique of Eurocentrism; the importance of gathering data in the field and verifying sources; the recognition of the cultural diversity of the Other"68 rechnen kann. Doch blieb seine Argumentationsweise - wie wir bereits sahen - allzu sehr an die von de Pauw ins Feld geführten Thesen gebunden, die der Bibliothekar Friedrichs II. oftmals nur mit anderen Vorzeichen versah, ohne ihnen eine neue argumentative (und wissenschaftlich begründbare) Fundierung zu geben. Selbst die schärfsten transatlantischen Gegner de Pauws bezogen weniger die Positionen Pernetys, deren Schwächen sie sehr wohl erkannten, als vielmehr eigene, amerikanische Stellungen, um die Debatte zwischen zwei europäischen „philosophes“ endgültig auszuweiten.

So wurde de Pauw nur in Europa zum Mann der Stunde - ungeachtet aller weiteren Publikationen von Pernety, die freilich kaum noch Wesentliches zur Debatte beitrugen. ${ }^{69}$ Sein Werk sollte noch für lange Jahre im Zentrum der von ihm ausgelösten hitzigen und weltweit erbittert geführten Debatten um Amerika und die Amerikaner stehen, bevor es dann in ein im Grunde bis in die jüngste Vergangenheit andauerndes Vergessen fiel. Selbst an der Berliner Akademie erinnert man sich nicht mehr an jene Debatte, die wohl im 18. Jahrhundert die weltweit größte Resonanz fand und die global folgenreichsten Konsequenzen zeitigte. Die in Europa dominanten Positionen wurden von de Pauw sehr scharf umrissen und wirkten weit ins 19. Jahrhundert. Nicht umsonst erklärte die französische Nationalversammlung in einem Dekret vom 26. August 1792 Cornelius de Pauw gemeinsam

67 Mannucci, Erica Joy: The savage and the civilised: observations on a dispute between an enlightened writer and an illuminist. In: Studies on Voltaire and the Eighteenth Century (Oxford) 303 (1992), S. 384.

68 Ebda.

69 Vgl. u. a. Pernety, Antoine-Joseph: Examen des Recherches philosophiques sur les Américains et de la Défense de cet ouvrage. 2 Bde. Berlin: G.J. Decker, Imprimeur du Roi 1771. 
mit anderen um die Freiheit der Völker verdienten Persönlichkeiten, zu denen auch George Washington zählte, zum „citoyen français““. ${ }^{70}$ An den von Napoleon zu Ehren de Pauws in Xanten aufgestellten Obelisken hatte ich Sie bereits aufmerksam gemacht. Napoleon, der die Sklaverei im französischen Kolonialreich wieder einführte und die Haitianische Revolution durch die Entsendung eines großen Heeres blutig niederzuschlagen versuchte, wusste, was er an seinem Abbé aus dem Xantener Stift hatte.

Von Beginn an hat sich die unmittelbar nach Erscheinen von de Pauws erstem Band einsetzende Rezeption in der europäischen wie in der außereuropäischen République des Lettres des 18. und beginnenden 19. Jahrhunderts auf die These von der essentiellen und von Natur aus angelegten Inferiorität der Neuen Welt und ihrer Bewohner konzentriert. Gewiss nicht ohne Grund wurde bis ins 20. Jahrhundert ein Verständnis des Werks als „probably the most scathing denunciation of America and everything American that was ever written“ perpetuiert. ${ }^{71}$ Wie wir sahen, hatte de Pauw schon auf der ersten Seite seiner Recherches philosophiques keinen Zweifel daran gelassen, dass alles auf der anderen ,Hälfte des Globus' von Natur aus ,defiguriert', degeneriert' und ,monströs ${ }^{6}$ sei. ${ }^{72}$ So war es dieser zentrale Aspekt und nicht die Warnungen de Pauws vor einer exzessiven Zerstörungsmacht der Wissenschaft oder einer extremen Bedrohung Europas durch weltumspannende Pandemien, welcher sich in der Diskussion um die Recherches philosophiques sur les Américains festsetzte.

Zweifellos - und eine Vielzahl von Untersuchungen hat dies deutlich herausgearbeitet - stand Cornelius de Pauw hier in einer Diskurstradition, die zum einen auf das gigantische Werk der Histoire naturelle Buffons zurückgeht, ${ }^{73}$ andererseits aber Argumentationslinien aufnimmt, die bis in die frühen Debatten

70 Vgl. hierzu Moureau, François: L’Amérique n’a aucun avenir, S. 68.

71 Church, Henry Ward: Corneille De Pauw, S. 179.

72 Pauw, Cornelius de: Recherches philosophiques sur les Américains, Bd. I, S. a2v.

73 Vgl. hierzu u. a. Church, Henry Ward: Corneille De Pauw, S. 189 und passim; Duchet, Michèle: Anthropologie et histoire au siècle des Lumières. Buffon, Voltaire, Rousseau, Helvétius, Diderot. Paris: Flammarion 1971, S. 206; Tietz, Manfred: Amerika vor der spanischen Öffentlichkeit des 18. Jahrhunderts. Zwei Repliken auf de Pauw und Raynal: Die „Reflexiones imparciales“ von Juan Nuix y Perpiñá und die „México conquistada“ von Juan de Escoiquiz. In: López de Abiada, José Manuel / Heydenreich, Titus (Hg.): Iberoamérica. Historia - sociedad literatura. Homenaje a Gustav Siebenmann. Bd. 2. München: W. Fink 1983, S. 991-993; oder Ventura, Roberto: Lectures de Raynal en Amérique latine au XVIII ${ }^{\mathrm{e}}$ et au XIX ${ }^{\mathrm{e}}$ siècles. In: Lüsebrink, Hans-Jürgen / Tietz, Manfred (Hg.): Lectures de Raynal. L'“Histoire des deux Indes, en Europe et en Amérique au XVIII ${ }^{e}$ siècle. Actes du colloque de Wolfenbüttel. Oxford: The Voltaire Foundation 1991, S. 341-359. 
zu Beginn des 16. Jahrhunderts zwischen Las Casas und Sepúlveda zurückreichen. Insofern beziehen sie auch Beschreibungs- und Diskurselemente von Aristoteles' ebenso berühmter wie berüchtigter Rechtfertigung einer gleichsam naturhaft gegebenen Sklaverei mit ein. ${ }^{74}$ Die Einschreibung von de Pauws zweibändiger Schrift in diese doppelte Diskurstradition ist ebenso unbestreitbar wie die Tatsache, dass der zeitweilig am Hofe von Friedrich dem Großen Weilende zugleich eine Zuspitzung der Inferioritätsthese und deren radikale Ausweitung auf die Amerikaner, die indigene Bevölkerung der Neuen Welt betrieb. Von ihr durfte er annehmen, dass dies - bei aller Kritik an einem Europa, das seine unhinterfragte „supériorité“ auf allen Gebieten missbraucht habe ${ }^{75}$ - auf entschiedenen Widerspruch stoßen musste. Dieser kam nicht nur von all jenen, die sich - gleichviel, ob sie Rousseaus berühmtem Discours sur l'origine et les fondements de l'inégalité parmi les hommes ${ }^{76}$ nahestanden oder nicht - als Anhänger der These vom ,edlen Wilden“ verstanden. Denn weder vom „bon sauvage“, vom „Edlen Wilden“, noch von dem, was Bernardin de Saint-Pierre später als die Harmonies de la nature bezeichnen und in einem mehrbändigen Werk bearbeiten sollte, ${ }^{77}$ ist auch nur das Geringste zu spüren.

Grundsätzliche und weit über den Horizont Pernetys hinausgehende Einund Widersprüche gegen Cornelius de Pauws Thesen ließen daher noch im 18. Jahrhundert nicht lange auf sich warten. ${ }^{78}$ Auf die umfangreiche und für ihre Zeit bestens fundierte Geschichte der mexikanischen ,Antike“ des aus seiner neuspanischen Heimat ausgewiesenen Francisco Javier Clavijero waren wir in unseren Überlegungen bereits ausführlich eingegangen. ${ }^{79}$ Diese Historia antigua de México, in welcher Clavijero eindrucksvoll die Diversität der indigenen

74 Am deutlichsten hat diese Traditionslinie herausgearbeitet Gerbi, Antonello: La Disputa del Nuovo Mondo, S. 99-109.

75 Pauw, Cornelius de: Recherches philosophiques, Bd. I, S. a3r.

76 Vgl. Rousseau, Jean-Jacques: Discours sur l'origine et les fondements de l'inégalité parmi les hommes. In (ders.): Euvres complètes. Bd. III. Edition publiée sous la direction de Bernard Gagnebin et Marcel Raymond avec, pour ce volume, la collaboration de François Bouchardy, Jean-Daniel Candaux, Robert Derathé, Jean Fabre, Jean Starobinski et Sven Stelling-Michaud. Paris: Gallimard 1975; vgl. in diesem Zusammenhang zur Epistemologie von Auge und Ohr Ette, Ottmar: Literatur in Bewegung, S. 119-192.

77 Vgl. Ette, Ottmar: Romantik zwischen zwei Welten, S. 72-96.

78 Vgl. hierzu ausführlich Ette, Ottmar: Archeologies of Globalization. European Reflections on Two Phases of Accelerated Globalization in Cornelius de Pauw, Georg Forster, GuillaumeThomas Raynal and Alexander von Humboldt. In: Culture \& History Digital Journal (Madrid) I, 1 (June 2012) <http://dx.doi.org/10.3989/chdj.2012.003> (20 pp.).

79 Vgl. Clavijero, Francisco Javier: Storia Antica del Messico. 4 Bde. Cesena: Gregorio Biasani 1780. 
Kulturen Amerikas auf dem Gebiet des heutigen Mexiko aufzeigte, stellt sicherlich die ausführlichste und in ihren Folgen glanzvollste amerikanische Replik innerhalb der Berliner Debatte um die Neue Welt dar.

Mit der Veröffentlichung seines altamerikanistischen Grundlagenwerks gelang es diesem neuspanischen Autor nicht nur, den Thesen von de Pauw, aber auch von Raynal oder Robertson dadurch entgegenzutreten, dass in breiter Vielfalt amerikanische Quellen einschließlich der Bilderhandschriften und anderer indigener Dokumente miteinbezogen wurden. Er trieb vielmehr - wie wir bereits sahen- eine Konstruktion der amerikanischen Vergangenheit voran, die als - im besten Sinne - Findung und Erfindung einer anderen Herkunft auch eine andere Zukunft für seine amerikanische Heimat ermöglichen sollte. Die präkolumbischen Kulturen erschienen hier nicht länger als vernachlässigbare Randerscheinungen der Menschheitsgeschichte, sondern stellten sich selbstbewusst als amerikanische Antike einer europäischen Antike gegenüber. So wurden die indigenen amerikanischen Kulturen wieder in Bewegung gesetzt und eröffneten neue Perspektiven und Einsichten in eine andere, von Amerika aus zu gestaltende Zukunft. Dass die kreolischen Eliten als soziale Trägerschichten der Unabhängigkeitsrevolution in den spanischen Gebieten Amerikas diese Vorgaben bestenfalls propagandistisch für sich ausnutzen, zugleich aber in ihren politischen Konsequenzen nicht wirksam werden ließen, steht freilich auf einem anderen Blatt der kontroversen Geschichte der amerikanischen Hemisphäre.

Doch entwickelte sich die vielleicht entscheidende Widerstandsfront gegen die Vorstellungen de Pauws ausgehend von Berlin selbst. Denn es wäre ein Leichtes zu belegen, dass den in der Berliner Debatte vorgetragenen Positionen bereits jene Schriften, die der „philosophe voyageur“ Alexander von Humboldt wenige Jahre nach der Rückkehr von seiner Reise in die amerikanischen Tropen (1799-1804) veröffentlichte, den wissenschaftlichen Todesstoß versetzten. Doch möchte ich an dieser Stelle unserer Vorlesung noch nicht zu Alexander von Humboldt kommen, sondern uns zunächst - wie versprochen - mit einem weiteren, dem dritten Bestseller der Lumières beschäftigen, den ein weiterer der berühmten Abbés aus der französischen Provinz gemeinsam mit einem ganzen Stab an Mitarbeitern verfasst hatte. Dieser Enzyklopädie der kolonialen Expansion Europas über die damals bekannte Welt wollen wir uns zum Abschluss dieses Kapitels widmen.

Halten wir zunächst einmal fest: Es kann kein Zweifel daran bestehen, dass Berlin und Potsdam durch die Recherches philosophiques sur les Américains und die sich anschließenden Debatten zwischen Antoine-Joseph Pernety, Zaccaria de Pazzi de Bonneville, Giovanni Rinaldo Carli, Delisle de Sales, Francisco Javier Clavijero, Drouin de Bercy und vielen anderen zeitweise ins Zentrum einer internationalen Debatte über die außereuropäische Welt gerückt wurden. 
Diese setzte sich bis weit ins 19. Jahrhundert hinein fort. Aus heutiger Sicht lässt sich dieser Zeitraum zweifellos als eine ideengeschichtlich bedeutungsvolle Periode begreifen, die freilich innerhalb der Geschichtsschreibung wie in der kollektiven Erinnerung ebenso einem weitgehenden Vergessen anheimfiel wie die Kolonialpolitik Brandenburgs beziehungsweise Preußens im ausgehenden 17. und beginnenden 18. Jahrhundert.

Wie sehr die internationalen Debatten vor dem Hintergrund der britischen und französischen, aber auch spanischen oder russischen Forschungsreisen der zweiten Phase beschleunigter Globalisierung die Bedeutung außereuropäischer Gegenstände im Allgemeinen und von Fragen, die sich mit der neuen Welt beschäftigten, im Besonderen veränderte, mag ein kurzer Blick in die französische Encyclopédie verdeutlichen. ${ }^{80}$ Im ersten, 1751 erschienenen Band dieses großen Gemeinschaftswerkes der europäischen Aufklärung wurden dem Stichwort „Amérique“ nur wenige Zeilen gewidmet: nicht mehr als für den Eintrag „Amer“ (bitter) und weit weniger als für „Améthyste“. Unter dem Stichwort „Amérique“ erfährt man, dass Amerika einer der vier Weltteile sei, 1491 (sic!) vom Genuesen Kolumbus entdeckt wurde und seinen Namen von „AméricVespuce Florentin“ erhielt, der die Neue Welt 1497 erreicht habe. ${ }^{81}$ Im Übrigen ist wenig mehr vermerkt, als dass sich der Kontinent in Südamerika und Nordamerika unterteile und dass der Süden neben vielen anderen aufgelisteten Kolonialerzeugnissen namentlich Gold und Silber, der Norden aber vor allem Biberfelle liefere. ${ }^{82}$

Im bereits erwähnten Supplementband der Encyclopédie, der 1776 in Amsterdam erschien, umfasst der Eintrag „Amérique“ hingegen nicht weniger als circa zwanzig dicht bedruckte Seiten. Der Umfang des Eintrags hat sich im Verlauf der beiden Jahrzehnte folglich versiebzigfacht. Der erste, deutlich umfangreichere der beiden Teile stammt aus der Feder von Cornelius de Pauw, der sich hier einer wesentlich weniger polemischen und weitaus moderateren Ausdrucksweise bedient. ${ }^{83}$ Er hatte sein Ziel einer internationalen Aufmerksamkeit ja längst erreicht. Kategorisch schloss de Pauw gleichwohl wie in seinen Recherches philosophiques mit der souveränen Geste des (quellen-)kritischen Aufklärers „les

80 Zur Encyclopédie vgl. neuerdings die Arbeit von Struve, Karen: Wildes Wissen in der „Encyclopédie“. Koloniale Alterität, Wissen und Narration in der französischen Aufklärung. Berlin Boston: Walter de Gruyter 2020.

81 Vgl. den Eintrag „Amérique“. In: Encyclopédie, ou Dictionnaire raisonné des Sciences, des Arts et des Métiers. Bd. 1. Paris: chez Briasson 1751, S. 356.

82 Ebda.

83 Vgl. den Eintrag „Amérique“. In: Supplément à l’Encyclopédie, ou dictionnaire raisonné des Sciences, des Arts et des Métiers, Bd. I. Amsterdam:Chez M.M. Rey, libraire, 1776, S. 343-362. 
anciennes relations“, die alten Chroniken, Dokumente und Berichte pauschal als völlig unglaubwürdig aus seinen Überlegungen aus, habe man es dort doch nicht nur mit der „crédulité d'un enfant“, sondern auch mit den „délires d'un vieillard“84 zu tun. Derartige Lektüren könne man folglich nur Kindern und Alten zumuten, die keinerlei Ansprüche an Wahrheit oder zumindest Wahrscheinlichkeit stellten. Damit verfügte der niederländische Abbé über ausreichend Platz, um an prominenter und prestigeträchtiger Stelle seine Thesen noch einmal detailliert einem internationalen Lesepublikum vorstellen zu können. Nicht von ungefähr hatten Amerika und die Debatten um die Neue Welt im Kontext einer neuen Globalisierungswelle nun auch im Umfeld der Encyclopédie erheblich an Raum gewonnen.

Es ist bedeutungsvoll und zugleich wenig überraschend, dass sich jenes andere, in seiner Entstehung wie in seiner „écriture“ weitaus komplexer angelegte französischsprachige Werk Raynals, das mit guten Gründen als Enzyklopädie der kolonialen Expansion Europas bezeichnet worden ist und sich zu einem der großen Bestseller des französischen 18. Jahrhunderts entwickeln sollte, ${ }^{85}$ vielerorts derselben Diskursstrategien und -traditionen bedient. Damit wollte es eine international breit gestreute Leserschaft für seinen auf mehreren tausend Seiten behandelten Gegenstand interessieren. So heißt es gleich in der "Introduction“ zum ersten Band der Histoire philosophique et politique des établissements et du commerce des européens dans les deux Indes in Formulierungen, die an die ersten Sätze von Cornelius de Pauws Recherches philosophiques sur les Américains oder seines Artikels für den Supplementband der Encyclopédie erinnern:

Es gibt kein anderes ebenso interessantes Ereignis für das Menschengeschlecht im Allgemeinen \& für die Völker Europas im Besonderen wie die Entdeckung der Neuen Welt \& der Seeweg nach Asien über das Kap der Guten Hoffnung. Damals begann eine Revolution im Handel, in der Macht der Nationen, in den Sitten, dem Gewerbefleiß und der Regierung aller Völker. [...]

Alles ist verändert \& muss sich weiter verändern. Aber die vergangenen Revolutionen \& jene, die folgen müssen: Sind sie oder werden sie für die menschliche Natur von Nutzen sein? Verdankt ihnen der Mensch in seinem Tagewerk mehr Ruhe, mehr Glück \& mehr Vergnügen? Wird sich sein Zustand verbessern oder lediglich verändern ${ }^{86}$

84 Ebda., S. 344.

85 Vgl. hierzu u. a. Lüsebrink, Hans-Jürgen: Die „Geschichte beider Indien“ - ein verdrängter Bestseller. In: Raynal, Guillaume [sic] / Diderot, Denis: Die Geschichte beider Indien. Ausgewählt und erläutert von Hans-Jürgen Lüsebrink. Nördlingen: Franz Greno Verlag 1988, S. 329-347.

86 Raynal, Guillaume-Thomas: Histoire philosophique et politique des établissements et du commerce des européens dans les deux Indes. Tome cinquième. Genf: Chez Jean-Léonard Pellet, Imprimeur de la Ville \& de l'Académie 1781, Buch 1, S. 1 f. 
Mit diesen Worten knüpfte Guillaume-Thomas Raynal, der de Pauws Werk sehr gut kannte, mit kaum veränderten Formulierungen an den Diskurs von der weltgeschichtlich herausragenden Bedeutung der sogenannten Entdeckung Amerikas an,. Er erweiterte die, westindische‘ Perspektive aber programmatisch durch die ,ostindische“ und rückte den Handel - wie schon im Titel seiner Kolonial-Enzyklopädie vermerkt - in eine wichtige, ja entscheidende Stellung im Hinblick auf jene Umwälzungen, die die Welt seit dem Ausgang des 15. Jahrhunderts so fundamental verändert hätten. Zugleich stellte er die philosophische Frage nach den Veränderungen für das Leben des Menschen und sein Glück selbst, fragte also danach, wie sich die Umwälzungen im europäischen Handel mit den Kolonien im Westen wie im Osten Europas auf die Zufriedenheit des (europäischen) Menschen ausgewirkt hätten.

Der Blick des aus der südfranzösischen Rouergue stammenden Philosophen orientiert sich damit am Handel und an dessen Konsequenzen in einer sich beständig verändernden Welt inmitten aller Umwälzungen, die sich seit dem Ausgang des 15. Jahrhunderts ergeben hätten. Die Entdeckung des Seewegs nach Indien wie die Entdeckung der Neuen Welt bilden jene Ereignisse, die alle gesellschaftlichen Verhältnisse in einen raschen und in seinen Folgen unabsehbaren Wandel einbezogen hätten. Handel und Wandel gehen Hand in Hand! Doch dieser Blick auf die erste Phase beschleunigter Globalisierung wurde ergänzt um die Einsicht, dass sich an die von ihr ausgelösten „Révolutions“ in Gegenwart und Zukunft neuerliche anschließen würden, die weitere grundlegende Umwälzungen mit sich bringen müssten. Deren Auswirkungen auf das Glück und den Wohlstand der Menschheit aber gelte es erst noch abzuwägen und abzuwarten, bevor man sich ein abschließendes Urteil erlauben könne. Denn Raynal wusste sich und seine Zeitgenossen in einer offenen globalgesellschaftlichen Entwicklung, die weit davon entfernt war, früheren geschichtlichen Vorbildern zu folgen.

Guillaume-Thomas Raynal verfasste seine Histoire des deux Indes im Bewusstsein jener Beschleunigungen und Veränderungen, die sein Zeitalter in der zweiten Hälfte des 18. Jahrhunderts fundamental erfasst hatten. Er war sich der beispiellosen Herausforderungen für eine zusammenwachsende Menschheit in einer globalgesellschaftlichen Epoche, die zugleich im Zeichen der Aufklärung stand, höchst bewusst und erkannte die ungeheure Wucht, welche von diesen „Révolutions“ ausgehen musste. Damit inszeniert das Incipit der Histoire des deux Indes eine Archäologie der Globalität aus dem Bewusstsein einer im Verlauf des vielbändigen Werkes immer wieder herausgearbeiteten verdoppelten Globalisierung: jener des ausgehenden 15. und beginnenden 16. Jahrhunderts einerseits und jener der zweiten Hälfte des 18. Jahrhunderts andererseits. 
Aber wusste man, wohin die Reise ging? Est-ce que l'on sait où l'on va?, könnten wir mit Diderots Jacques le fataliste et son maître fragen? ${ }^{87}$ Die Zukunft dieser Umwälzungen - wie auch mit ihr die Geschichte selbst - erschien als vollständig offen. Die entscheidende Antriebskraft und Dynamik einer derartigen Welt im Wandel aber - dies erkannte der französische „philosophe“ sehr genau - bildete der Welthandel.

So wirft die Figur des Philosophen, dessen Stimme die heterogenen, oft in Widersprüchen sich verfangenden Teile der Histoire des deux Indes immer wieder zusammenhält, zunächst einen Blick auf das Europa vor der Epoche der Entdeckungen („l'Europe avant les découvertes“88). Sie tut dies, um sodann einen höheren Beobachterstandpunkt $\mathrm{zu}$ gewinnen, der aus einer geradezu extraterrestrischen, die Erde insgesamt umspannenden Perspektive die fundamentale Bedeutung eines globalisierten Handels für den gesamten Erdball unterstreicht. Die planetarische Metaphorologie dieses Blickes eines französischen Philosophen aus dem letzten Drittel des 18. Jahrhunderts ist bemerkenswert:

Erhaben über allen menschlichen Erwägungen schwebt man dann über der Atmosphäre \& erblickt den Globus unter sich. Von dort aus lässt man Tränen tropfen auf das verfolgte Genie, auf das vergessene Talent, auf die unglückselige Tugend. [...] Von dort aus erblickt man das stolz erhobene Haupt des Tyrannen, das sich neigt \& mit Schlamm bedeckt, während die bescheidene Stirne des Gerechten das Himmelsgewölbe berührt. Von dort aus konnte ich wirklich aufschreien Ich bin frei \& mich auf der Höhe meines Gegenstandes fühlen. Von dort aus konnte ich endlich zu meinen Füßen diese schönen Gegenden erblicken, wo die Wissenschaften \& die Künste erblühen \& welche die Finsternisse der Barbarei so lange bedeckt hielten, \& so fragte ich mich: Wer hat diese Kanäle gegraben? Wer hat diese Ebenen trockengelegt? Wer hat diese Städte gegründet? Wer hat diese Völker zusammengeführt, gekleidet, zivilisiert? \& sodann haben mir alle Stimmen der aufgeklärten Menschen, die sich darunter befinden, geantwortet: Es ist der Handel, es ist der Handel. ${ }^{89}$

Diese literarische Inszenierung eines über der Erde, über der Atmosphäre schwebenden Philosophen, der den Astronautenblick aus dem Kosmos auf unseren Planeten, auf den ,Lonely Planet“ vorwegnimmt, ist ebenso spektakulär wie aufschlussreich. Denn der Erdball erscheint, um nicht nur ein Denken der Globalität, sondern auch der zeitgenössischen Globalisierung in Szene zu set-

87 Vgl. hierzu auch das Denis Diderot gewidmete Kapitel im ersten Band der reihe „Aula“ von Ette, Ottmar: ReiseSchreiben. Potsdamer Vorlesungen über die Reiseliteratur (2020), S. $169 \mathrm{ff}$. sowie S. 222.

88 Raynal, Guillaume-Thomas: Histoire philosophique et politique des établissements et du commerce des européens dans les deux Indes. Tome cinquième. Genf: Chez Jean-Léonard Pellet, Imprimeur de la Ville \& de l'Académie 1781, Buch 1, S. 2.

89 Ebda., Buch 1, S. 3 f. 
zen und zugleich die Umwälzungen des Handels mit einem anzustrebenden Gesellschaftssystem zu verbinden, in welchem die Barbarei im Lichte der Zivilisation verschwinden und die Tyrannei ein für alle Mal den Kopf senken werde. Eine Epoche werde anbrechen, in welcher sich eine freiere Gesellschaft im Zeichen eines freien Welthandels fortentwickeln werde. Alle Unterdrückungen aufklärerischen Denkens würden dann ein Ende finden.

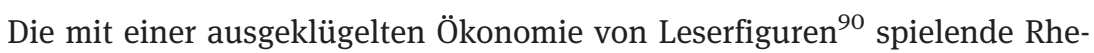
torik der Histoire des deux Indes vermochte nicht nur, eine im Vergleich zu den Recherches philosophiques de Pauws noch größere Resonanz beim Lesepublikum zu entfalten, ${ }^{91}$ sondern vor allem einen weitaus größeren räumlichen, thematischen und philosophischen Bogen zu spannen. Dies geschah nicht zuletzt auf Grund der Aufnahme vieler statistischer Daten, die Raynal, Diderot und die zahlreichen Mitarbeiter und Korrespondenten beibrachten. Das europäische und in Ansätzen weltweite Netzwerk an Korrespondenten verschaffte diesem Kollektivprojekt für mehrere Jahrzehnte den Status eines Referenzwerks über die außereuropäische Welt und den Welthandel, wie er sich in der zweiten Hälfte des 18. Jahrhunderts rund um das Zentrum Europa entwickelte. Guillaume-Thomas Raynal, der sich während seiner Exilierung aus Frankreich freilich nur kurz am Hofe Friedrichs des Großen aufhielt und in Deutschland eine gegenüber Frankreich wesentlich reserviertere Aufnahme fand, hatte seit der Erstausgabe seiner Histoire des deux Indes im Jahr 1770 das Werk des holländischen Abbé am preußischen Hof zunehmend in den Schatten gestellt.

Doch die Rezeption des Hauptwerks von Guillaume-Thomas Raynal beschränkte sich keineswegs auf Frankreich, Preußen oder Europa, sondern reichte weit in die transatlantische Welt hinein. In seiner berühmten, 1815 in seinem Zufluchtsort Kingston verfassten Carta de Jamaica verlieh Simón Bolívar seiner Hoffnung auf eine nationale und kontinentale Befreiung vom spanischen Joch Ausdruck, wobei er sich explizit auch auf jenen Autor bezog, dessen Name seit 1780 die Titelseite der erstmals 1770 veröffentlichten Histoire des deux Indes zierte:

90 Vgl. Ette, Ottmar: Figuren und Funktionen des Lesens in Guillaume-Thomas Raynals „Histoire des deux Indes“. In: Briesemeister, Dietrich / Schönberger, Axel (Hg.): Ex nobili philologorum officio. Festschrift für Heinrich Bihler zu seinem 80. Geburtstag. Berlin: Domus Editoria Europaea 1998, S. 589-610.

91 Vgl. u. a. Bancarel, Gilles: Le succès inattendu d'un Rouergat au XVIII ${ }^{\mathrm{e}}$ siècle. In: Procès Verbaux des Sciences de la Société des Lettres, Sciences et Arts de l'Aveyron (Rodez) XLV, oㅡ fasc. (1988), S. 218-225; sowie (ders.): G. Thomas Raynal: de la séduction à la sévérité. In: Revue de Rouergue (Rodez) 28 (hiver 1991), S. 477-488. 
Trotz alledem werden die Mexikaner frei sein, weil sie die Partei des Vaterlandes ergriffen haben, verbunden mit dem Entschlusse, entweder ihre Vorfahren zu rächen oder ihnen ins Grab zu folgen. Denn sie sprechen mit Raynal: Die Zeit ist endlich gekommen, den Spaniern Folter mit Folter zu vergelten und diese Rasse von Mörderbanden in ihrem eigenen Blute oder im Meere zu ertränken. ${ }^{92}$

In diesem für ein Verständnis des „Libertador“ grundlegenden Text griff der Vertreter der jungen kreolischen Eliten des künftigen Amerika, des künftigen Venezuela, ohne weitere Erläuterungen auf den Namen des französischen Philosophen nicht etwa zurück, um seine politischen und ideologischen Überzeugungen zu begründen. Vielmehr bediente er sich seines Namens als Waffe im Kampf der Texte und Diskurse gegen ein Spanien, dessen zwischenzeitlich verstärkte Truppen in den Kolonien eine Reihe von Siegen über die Aufständischen errungen hatten. Der Kampf um die Unabhängigkeit der spanischen Kolonien Amerikas stand auf Messers Schneide; und da galt das Werk Raynals gerade mit seinen scharfen Formulierungen, für die Denis Diderot gesorgt hatte, als ein aufwühlendes Manifest des Kampfes gegen jede Form von Tyrannei.

Gewiss handelte es sich beim Verweis auf Raynal um den Rückgriff auf eine eher zweischneidige Waffe. Denn einerseits war der französische „philosophe“ - der bei den aufgeklärten amerikanischen Kreolen noch immer unbestritten als der Verfasser der Histoire des deux Indes galt - für seine vehementen Ausfälle gegen die Spanier und ihr ebenso ungerechtes wie ineffizientes Kolonialsystem berühmt geworden. Doch wussten die Angehörigen der kreolischen Oberschicht andererseits auch um seine Angriffe auf die Dekadenz, die Trägheit und Unfähigkeit der Bewohner des südlichen Amerika - wohlgemerkt unter Einschluss der Kreolen, denen er wie de Pauw oder andere europäische Autoren des 18. Jahrhunderts vorwarf, sich nicht selbst regieren und eigene Regierungsformen entwickeln zu können.

Derlei Anschuldigungen hatten den Ruf und das Prestige des französischen Philosophen in den intellektuellen Zirkeln der amerikanischen Kolonien allerdings stark beschädigt. Nicht umsonst hatten in Neuspanien bestimmte ,mexikanische“ Vordenker wie Francisco Xavier Clavijero oder Fray Servando Teresa de Mier y Guerra eine Polemik gegen europäische Philosophen in Gang gesetzt. Sie wandten sich gegen jene Vertreter der europäischen Geisteswelt, welche die abwertenden Urteile Montesquieus oder Buffons gegenüber Amerika noch verschlimmert hatten und damit für eine andere Seite der Dialektik der Aufklärung verantwortlich zeichneten.

92 Bolivar, Simon: Carta de Jamaica. The Jamaica Letter. Lettre à un Habitant de la Jamaïque. Caracas: Ediciones del Ministerio de Educación 1965, S. 58. 
Wenn die Rezeption des Raynal'schen Werks in Lateinamerika auch von einer grundlegenden Ambivalenz gekennzeichnet war, so konnte die Histoire des deux Indes - und insbesondere ihre zahlreichen gegen die spanische Kolonialverwaltung gerichteten Anklagen - doch als eine wichtige Waffe für jene, die für eine politische Selbständigkeit der spanischen Kolonien kämpften, von großem Nutzen sein. Denn sie untergrub die Legitimität des spanischen Mutterlandes in seinen überseeischen Kolonien. Die angeführte Passage belegt, dass nicht nur Simón Bolivar um die subversive Kraft dieses vielgestaltigen und widersprüchlichen Werks wusste. Auch die spanische Kolonialverwaltung war sich dieser Gefahr bewusst, so dass man bald versuchte, ein Gegengewicht zu dieser gefährlichen Wirkung von Raynals Attacken auf die aufgeklärte kreolische Elite zu schaffen.

Dies mag die dauerhaften Anstrengungen von spanischer Seite erklären, eine offizielle Geschichte des eigenen Kolonialreichs vorzulegen. ${ }^{93}$ Diese um Sachlichkeit bemühten Gegendarstellungen beruhten auf der spanischen Krone allein zugänglichen Informationen - und hierzu zählten nicht nur die Kolonialarchive, sondern auch eine Reihe von Berichten spanischer Reisender, die in ihrem Auftrag die Kolonien besuchten. ${ }^{94}$ Aller Widersprüche und Ambivalenzen zum Trotz, welche die Wirkung der Histoire des deux Indes in den Kreisen der Hispanoamerikaner beeinträchtigten, standen Raynal und sein bekanntestes Werk doch symbolhaft für eine Befreiung aus kolonialer Unterdrückung, waren doch viele der am Befreiungskampf auf hispanoamerikanischer Seite Beteiligten mit den berühmt gewordenen Anklagen oder „harangues“ in dieser Enzyklopädie der europäischen Expansion vertraut. Auch in der Neuen Welt verfehlte die revolutionäre Rhetorik der Alten Welt ihre Wirkung nicht und fand Eingang in den Diskurs der „Libertadores“. Da konnten alle spanischen Gegendarstellungen, die Teil des Disputs um die Neue Welt, aber nicht der Berliner Debatte um die Neue Welt waren, nichts Entscheidendes ausrichten.

Zweifellos ist die in der Carta de Jamaica zu beobachtende Instrumentalisierung und Lesart Raynals nur eine unter unzähligen Einverleibungen, die

93 Vgl. hierzu Tietz, Manfred: L’Espagne et l'Histoire des deux Indes de l'abbé Raynal. In: Lüsebrink, Hans-Jürgen / Tietz, Manfred (Hg.): Lectures de Raynal. L'Histoire des deux Indes en Europe et en Amérique au XVIIIe siècle. Actes du Colloque de Wolfenbüttel. Oxford: The Voltaire Foundation 1991, S. 99-130.

94 Vgl. hierzu Tietz, Manfred: Amerika vor der spanischen Öffentlichkeit des 18. Jahrhunderts. Zwei Repliken auf de Pauw und Raynal: Die „Reflexiones imparciales“ von Juan Nuix y Perpiñá und die „México conquistada“ von Juan de Escoiquiz. In: López de Abiada, José Manuel / Heydenreich, Titus (Hg.): Iberoamérica. Historia - sociedad - literatura. Homenaje a Gustav Siebenmann. Bd. 2. München: W. Fink Verlag 1983, S. 989-1016. 
sich zwischen dem letzten Drittel des 18. und dem ersten Drittel des 19. Jahrhunderts in den amerikanischen Kolonien Spaniens beobachten lassen. Simón Bolívars Lektüre ist ein schönes Beispiel für einen ,interessierten‘ Lektüretyp, der uns freilich oftmals mehr über den Leser als über das Gelesene zu sagen vermag. Doch gibt es auch andere, vielleicht weniger spektakuläre, aber darum nicht weniger aufschlussreiche Lektüretypen. So wäre es - um bei dem von Bolívar erwähnten Raum Neuspaniens zu bleiben - leicht zu belegen, wieviel der erste von einem Hispanoamerikaner in Hispanoamerika geschriebene Roman, El Periquillo Sarniento von José Joaquín Fernández de Lizardi, einer aufmerksamen Lektüre der Histoire des deux Indes verdankt. ${ }^{95}$

Von Simón Bolivar im Norden bis hin zu Domingo Faustino Sarmiento im Süden des südamerikanischen Subkontinents, von den verschiedenen Repräsentanten einer politischen und philosophischen Aufklärung in Mexiko bis hin zu Vertretern der Raynal'schen Ideen in Kanada: diese Enzyklopädie des europäischen Kolonialismus provozierte auf dem gesamten amerikanischen Kontinent eine Vielfalt verschiedener, aber stets produktiver Lektüren. Dieser Bestseller der Lumières wurde zweifellos zu einer Triebfeder von Umgestaltungen. Wie ein in Wolfenbüttel veranstaltetes Raynal-Symposium zeigen konnte, war die Wirkung des Raynal'schen Oeuvre ebenso groß und weitverzweigt wie die Divergenz der von ihm ausgelösten Lektüren. ${ }^{96}$ Das sicherlich nicht brisanteste, aber wohl doch weitreichendste und erfolgreichste Werk des französischen Abbé brachte eine Vielzahl von Lesarten in beiden Welten hervor, die den Einfluss der Schriften von Cornelius de Pauw doch bei weitem überstrahlten.

Mag die Geschichte dieser Lektüren auch nichts von ihrer Faszination eingebüßt haben, so gilt doch, dass dieser französische Bestseller der zweiten Hälfte des 18. Jahrhunderts seinerseits auf einem weitgespannten Gewebe von Lesevorgängen aufbaute, deren Komplexität bis heute überrascht und beeindruckt. In ihrem Bezug zur Tradition der Reisesammlungen präsentiert sich die Histoire des deux Indes unseren heutigen Augen als eine Fortsetzung und zugleich Radikalisierung der Histoire générale des voyages des Abbé Prévost, den Raynal buchstäblich plünderte. Eine Reihe von Forschungen haben detailliert aufgezeigt, in welchem Maße Raynal, der „Abbé der Neuen Welt“, nicht gezögert hatte, sich bei der Histoire générale zu bedienen und zahlreiche Passagen dieses wichtigen Bezugstextes dekontextualisierend zu übernehmen.

95 Vgl. zu diesem herausragenden Roman das entsprechende Kapitel in Ette, Ottmar: Romantik zwischen zwei Welten, S. 285-334.

96 Vgl. Lüsebrink, Hans-Jürgen / Tietz, Manfred (Hg.): Lectures de Raynal. L'Histoire des deux Indes en Europe et en Amérique au XVIIIe siècle. Actes du Colloque de Wolfenbüttel. Oxford: The Voltaire Foundation 1991. 
Die Histoire des deux Indes ist eine wahre Kriegsmaschine, eine „machine de guerre“. Zwischen den Polen schöpferischer Umsetzung und simplen Plagiats oszillierend, erweist sich die „écriture Raynals“ doch stets als hochdosierte Anverwandlung und Aneignung fremder Texte. Schreiben und Neuschreiben, Lesen und Neulesen werden zu Prozessen, die sich nicht mehr voneinander abtrennen lassen. Sie produzieren eine Intertextualität, die durch die beschleunigte Proliferation fremder Textfragmente und verschiedenster Informationsquellen seit der ersten Ausgabe der Histoire des deux Indes im Jahr 1770 zunehmend zentrifugalen Charakter erhielt und so das in den frühen Rezeptionszeugnissen bereits feststellbare Bedürfnis nach einer das gesamte Werk zentrierenden Autorfigur noch erhöhte.

Dieses Bedürfnis nach diskursiver Zentralisierung leitete schließlich zu einer wachsenden Autorisierung des über die verschiedenen Ausgaben in ständiger Expansion befindlichen kollektiven Textes über und wir werden darauf am Ende dieses Kapitels nochmals zurückkommen. In gewisser Weise benötigte die Histoire des deux Indes nicht so sehr die Figur eines Kompilators, als vielmehr jene eines Gewährsmannes, eines Autors im modernen Wortsinn. Guillaume-Thomas Raynal, der mit allen Wassern der République des Lettres des 18. Jahrhunderts gewaschen war, verlieh seinem Text eine größere Autorisierung und Autorität, indem er von Ausgabe zu Ausgabe der Figur eines Autors schärfere Konturen und schließlich auch seinen Namen gab.

Diese Strategie erwies sich als überaus wirksam, denn der Abbé aus dem Aveyron wurde bis zu seiner berüchtigten Adresse à l'Assemblée Nationale von 1791 nicht nur als einer der großen „philosophes“, sondern auch als einer der „Väter der Revolution“ verehrt. Gleichzeitig handelte es sich um eine Textstrategie von großer Subversivität, die das gesamte Werk mit einer hohen Ausstrahlungskraft versah. Die Histoire des deux Indes war ein ungeheurer Bucherfolg, ihr vermeintlich einziger Autor, Raynal, ein zugleich von der französischen Geheimpolizei gejagter und in ganz Europa berühmter, gewiss auch berüchtigter, in jedem Falle aber viel- und heißdiskutierter Mann.

Raynals Unterfangen veränderte die Leselandschaften des Aufklärungszeitalters. Denn die Frage der Beziehung zwischen Europa und den außereuropäischen Gebieten erhielt im historischen Kontext der damaligen Globalisierungsphase zunehmend Zugang zu den breitesten Kreisen der Bevölkerung - dies dürfen wir gerade bezüglich des publizistischen Echos nicht vergessen! Ich möchte Ihnen daher auch gerne zwei Zeugnisse der internationalen Reaktion auf Raynal, die aus Deutschland stammen, präsentieren, um daran auch die aufklärerische Bedeutung Raynals und seiner Überlegungen zu erkennen. So erschien nach seinem Tod im Genius der Zeit, einem in Altona erscheinenden Journal, im No- 
vember 1796 ein Nachruf auf den französischen Philosophen, der für unsere Fragestellung interessant ist:

Wenn das menschliche Geschlecht je einen aufrichtigen Freund, einen warmen Verteidiger seines Rechts und einen eifrigen Arbeiter für sein allgemeines Wohl hatte, wer war es mehr als Wilhelm Thomas Raynal. - Mag doch Rousseau mit trügerischen Sophismen die Welt entzücken und zugleich den Bruder gegen den Bruder waffnen - mag er mit geprahlter Wahrheitsliebe Grundsätze aufstellen, die untereinander im Widerspruche zur Anarchie, zum Aufruhr und Verbrechen aufrufen - mag er sich als den wahren Freund seines Vaterlandes und seiner Mitbürger zeigen und den gerühmten Machtspruch tun: „Mancher liebt die Hottentotten, damit er nicht nötig habe, seine Nachbarn zu lieben“: Die Welt wird einst sein Herz erkennen und sein Verdienst sichten. [...] Der wahre Philanthrop, der feurige Sachwalter seines unterdrückten Geschlechts, gleich tugendhaft in seinem öffentlichen Wandel und in seinem Hause, in seinen Schriften und seinen Handlungen, der ist eines schönen Siegs über alle menschenfeindliche Philosophie, alle hypokritische Tugend gewiss. O Raynal! [...]

Raynals Werk ist nicht für jedermann überall gleich interessant. Die Franzosen, die Engländer und andere haben die Angriffe für überflüssig gehalten, die er auf den Aberglauben und die päpstliche Gewalt getan hat. Aber schrieb denn Raynal für den Franzosen? O nein, der Spanier und Italiener haben so gut ein Recht auf sein Wohlwollen als seine Landsleute, und jene wissen ihm recht herzlichen Dank, dass er gegen eine Herrschaft geeifert hat, unter deren unerträglichem Joche ihr Vaterland seufzt. Man hat es Raynal ferner vorgeworfen, dass er in seinen Beschreibungen zu ungenau und fehlerhaft gewesen sei. Dieser Vorwurf trifft ihn nicht so sehr als diejenigen, aus deren Nachrichten er geschöpft hat; er konnte nicht überall gewesen sein -

aber der Tadel verschwindet fast ganz, wenn man den unermüdeten Fleiß wahrnimmt, mit welchem er alles sammelte, verglich, aufklärte, Widersprüche hob und so eine Wahrscheinlichkeit aufstellte, die seine Bescheidenheit dennoch nie als Spruch angesehen wissen wollte, sondern wobei er es immer der eigenen Beurteilung der Leser überließ, zwischen dem einen oder dem andern zu wählen. ${ }^{97}$

Sie sehen also: Nicht nur für Simón Bolívar und die lateinamerikanische Unabhängigkeit war Guillaume-Thomas Raynal ein wichtiger Bezugspunkt, sondern auch für den deutschsprachigen Raum, wobei freilich ein Bewusstsein darüber verbreitet war, dass Raynals Leserschaft eine gesamteuropäische war! Weitaus weniger war der europäischen Leserschaft klar, dass Raynals Histoire des deux Indes auch in diesen „Indes“, in den Kolonialgebieten selbst, gelesen wurde. Diese Geschichte beider Indien war, wie wir heute sagen dürfen, ein weltumspannendes Ereignis, insofern sie sich nicht nur mit weltumspannenden Entwicklungen auseinandersetzte, sondern auch eine tendenziell weltumspannende Rezeption erfuhr. Dies war bei Cornelius de Pauw weitaus weniger der Fall.

97 Nachruf auf Guillaume-Thomas Raynal. In: Genius der Zeit (1796). Ich entnehme dieses Zitat der Ausgabe der Geschichte beider Indien von Lüsebrink, S. $313 \mathrm{ff}$ :. 
Aufschlussreich ist in obigem Zeugnis, wie sehr Raynal dem Genfer Rousseau vorgezogen wird, der letztlich nur Zwietracht gesät habe und bald schon von den Menschen vergessen sein würde. Interessant ist dies auch deshalb, weil diese beiden Autoren, Rousseau und Raynal, zwar die beiden großen Bestseller des Jahrhunderts verfasst haben, nur der eine von beiden - Rousseau aber tatsächlich einen langfristigen Ruhm ernten konnte, während Raynals Büste bald wieder aus dem Pantheon der großen Väter des Vaterlandes entfernt und buchstäblich ins Irrenhaus getragen wurde. Doch auch ohne diese diskreditierenden Akte, die dem Verhalten Raynals nach der Französischen Revolution galten, hätte die Geschichte beider Indien den epistemologischen Übergang zum 19. Jahrhundert nicht überlebt: Der weit gespannte Fächer des darin ausgebreiteten Wissens war zu wenig in einer direkten, konkreten Erfahrung fundiert.

Die Kritik an Raynal kam nicht erst im transatlantischen Netzwerk einer Aufklärung zwischen zwei Welten zustande. Von Beginn an hatte es scharfe Kritiken nicht nur in Frankreich, sondern auch in ganz Europa gegeben. Ein Beispiel hierfür - und aus der spezifischen Position der deutschen Geistesgeschichte mit ihrer zunehmend prononciert antifranzösischen Stoßrichtung mag Johann Gottfried Herder sein, der in einem Brief von Juni 1782 an Johannes Müller vom Eintreffen des Philosophen in Weimar berichtete. Diese Passage macht zugleich auf den enormen Bekanntheitsgrad Raynals, auf die hohe Akzeptanz des von den französischen Behörden Verfolgten in den deutschen Fürstentümern - später zeitweise ja auch in Brandenburg und Potsdam -, aber auch auf die gegenüber Frankreich vorgetragene Kritik am „Geist des Jahrhunderts“ von Seiten deutscher ,Intellektueller‘ aufmerksam:

Raynal ist hier gewesen, und mich freut's, dass Sie nicht hier waren. Es ist der geschwätzigste Deklamator, der mir im Leben vorgekommen ist, völlig die Blüte unseres Jahrhunderts - denn auch die Distel blüht! Übrigens ist nichts an ihm hochachtungswürdig als sein jargon philosophique et politique, nach dem er in Europa in jedem Kabinett so gut zu Hause ist wie in den beiden Indien und sehr fein seine Menschen zu finden und zu messen weiß. Er ist, vom Prinzen August begleitet, wie ein Gott hier angekommen und hat sich wie ein oracle politique et philosophique hier betragen. Wohl den Göttern und Orakeln! ${ }^{98}$

Herder gewährt uns in diesen Zeilen einen tiefen Einblick in die internationale Rezeption des französischen „philosophe“ ebenso bei den Fürsten wie bei einem breiteren Lesepublikum. Raynal besaß einen Ruf wie Donnerhall. Zum damaligen Zeitpunkt - die dritte Ausgabe der Histoire des deux Indes war gerade

98 Herder, Johann Gottfried: Brief vom 1. Juni 1782. In Otto, Regina (Hg.): Herders Briefe in einem Band. Berlin: Aufbau-Verlag 1970, S. 224. 
erschienen - stand Raynal im Zenit seines internationalen Ruhms. Er wurde von den französischen Behörden verfolgt, erhielt gleichwohl aber insgeheim seine Bezüge („rentes“) unverändert ausbezahlt. Seine Kolonialismus-Kritik wurde trotz aller Unkenntnis und Verzerrung der Verhältnisse in den Kolonien doch zu einem Sprengstoff, der in der Tat auch gegen die Kolonialherren eingesetzt werden konnte. Man musste dabei nur vorsichtig vorgehen und es vermeiden, nicht einen Teil der eigenen Machtansprüche gleichzeitig mit der Verwendung dieses Sprengstoffes mit in die Luft zu sprengen.

Die „rhétorique incendiaire“ von Raynal beziehungsweise Diderot spielte in den Kolonien weit mehr noch als in Europa eine entscheidende Rolle. In Übersee wirkte sie in der Tat wie eine „machine de guerre“, die - fand sie erst die richtigen Leser - mögliche Aufstände beflügelte. Der Name Raynal stand in jedem Falle nicht nur in den Kolonien für die Vision vom Ende einer dreihundertjährigen kolonialen Unterdrückung; und diese Tatsache macht auf den hochgradig ambivalenten Charakter seines Werkes - ebenso des Textes selbst wie seiner Rezeption - aufmerksam:

Allem Anschein nach wird der Hof von Madrid niemals die Anzahl der Truppen vermindern, die er in Neuspanien unterhält: Aber der Anteil des öffentlichen Einkommens, welchen die Befestigungen auffressen, wird schon bald die Schätze nicht vergrößern, es sei denn, dass der Hof diese Schätze in der Kolonie selbst darauf verwendet, nützliche Niederlassungen zu gründen. Schon öffnen sich an den Ufern des Flusses Alvarado, wo sehr viel Bauholz gedeiht, große Werkstätten. Diese Neuerung sagt Glückliches voraus. Andere werden zweifellos diesem Beispiele folgen. Vielleicht wird Mexiko nach drei Jahrhunderten der Unterdrückung oder der Lethargie die hohe Bestimmung erfüllen, zu der es die Natur seit so langer Zeit rief. ${ }^{99}$

Mit diesen Worten einer „douce espérance“100 verlässt die Histoire des deux Indes des Abbé Raynal im letzten Abschnitt des sechsten Buches geographisch korrekt den nordamerikanischen Raum, um sich in der Folge dem Bereich Südamerikas zuzuwenden. Die zitierte Passage verdient unsere Aufmerksamkeit nicht nur aufgrund ihres Übergangscharakters, sondern vor allem, weil hier ein eigener Raum konstruiert wird, für den die Bezeichnung „le Mexique“ an die Stelle der kolonialspanischen „Nouvelle-Espagne“ tritt. Die kolonialspanische Bezeichnung „Neuspanien“ macht ganz wie bei der Titelfindung von Francisco Javier Clavijeros Historia antigua de México jener zukunftsgerichteten Bezeichnung „Mexiko“ Platz, welche auf die präkolumbische und damit vorspanische Bezeichnung zurückgreift.

99 Raynal, Guillaume-Thomas: Histoire des deux Indes, Bd. 3, S. 344. 100 Ebda. 
Diese neue Begrifflichkeit ist von großer Bedeutung: Mit dieser Verschiebung tritt zugleich einem Geschichtsraum von drei Jahrhunderten, der die Kolonialzeit als Zeit des Stillstands, der Untätigkeit und der Unterdrückung charakterisiert, der Raum einer zukünftigen eigenen Entwicklung entgegen. Innerhalb dieser könne - ob in kolonialer Abhängigkeit oder politischer Eigenständigkeit bleibt noch offen - unter dem Impuls einer sich entwickelnden Industrie die naturräumliche Ausstattung und Infrastruktur endlich genutzt und zum Wohle des künftigen Mexiko in Wert gesetzt werden. Repräsentiert der Begriff „Neuspanien“ paradoxerweise das zu überwindende Alte, so steht mit „Mexiko“ ein Begriff für die zukünftige Entwicklung ein, der auf die vor der spanischen Eroberung liegende präcortesianische Zeit zurückverweist. Damit lässt er einen Geschichtsraum entstehen, in welchem „Conquista“ und „Colonia“ im Grunde als Unterbrechung, ja als Fremdkörper innerhalb eines eigenen historischen Seins stehen, das sich aus der präkolumbischen Zeit ableitet. ${ }^{101}$

Die Position der Geschichte beider Indien ist freilich trotz allem ambivalent. In der wenige Jahrzehnte später losbrechenden Unabhängigkeitsrevolution ist der bewusste wie unbewusste Rückgriff auf die Zeit vor der Eroberung in der politischen Symbolik überall mit Händen zu greifen. Ja es gelingt den politischen Führern - beziehungsweise den kreolischen Eliten -, die indianischen Mythen neu für ihre eigenen politischen Interessen dienstbar zu machen und eine wahre aztekisierende Mode $^{102}$ auszulösen, mit welcher die Kolonialzeit sichtbar zum Verschwinden gebracht und die neue Nationalität im alten „Imperio Mexicano“ verankert werden sollte. In Raynals erstmals 1770 erschienener Histoire des deux Indes ist eine derartige Zeitstruktur inhaltlich jedoch nicht verankert. Am Ende des siebten Kapitels im sechsten Buch im Übergang zur Beschäftigung mit Geschichte und Gegenwart Neuspaniens hatte die für die Geschichtsschreibung der Histoire zentrale narrative Instanz die barbarischen Grausamkeiten der spanischen Eroberer im karibischen Raum gegeißelt und heiße Tränen vergossen über die längst verschwundene indigene Bevölkerung. Doch werden wenige Seiten später durch diese Erzählinstanz selbst die Vergangenheit der indianischen Völker und ihre differenzierten kulturellen Formen mit

101 In einer Vielzahl von Schriften - nicht zuletzt im Anfangskapitel von Sor Juana Inés de la Cruz o las trampas de la fe mit seiner Interpretation des Vizekönigreiches - hat Octavio Paz eine derartige, in seinen Augen bis heute anhaltende Geschichtsvision diagnostiziert und harte Kritik an ihr geübt.

102 Vgl. hierzu O’Gorman, Edmundo: Prólogo. In: Mier, Fray Servando Teresa de: Ideario politico. Caracas: Biblioteca Ayacucho 1978, S. xxv. Nicht zu Unrecht ist dort auch in politischer Hinsicht die Rede von einem damals angestrebten „imperio azteca liberal y parlamentario“ (S. xxvi). 
einem Federstrich beseitigt. So heißt es in der Geschichte beider Indien: „Ihre Rasse ist nicht mehr. Ich muss einen Augenblick an dieser Stelle verharren. Meine Augen füllen sich mit Tränen \& ich sehe nicht mehr, was ich schreibe.“103 Zur epistemologischen Bedeutung der Augen, die auch in dieser Passage nicht der Aufnahme fremder Informationen (von außen nach innen) dienen, sondern den Informationsfluss umkehren und (von innen nach außen) dem Lesepublikum Hinweise über die so geschaffene explizite Autorfigur geben, wäre hier viel anzumerken, doch müssen wir uns dem Ende dieses Kapitels zuwenden. ${ }^{104}$

Unter der Feder Raynals und Diderots begegnen wir erneut der Frage (und Problematik) aufklärerischer Kritik. Denn mit der Geste des aufgeklärten Philosophen und des erfahrenen Geschichtsschreibers, der es gewohnt ist, seine Quellen nicht für bare Münze zu nehmen, sondern sie einer tiefgründigen Kritik zu unterziehen, werden alle Berichte der Spanier über jene für die europäischen Leser wundersame Welt, die sie eroberten und zugleich zerstörten, ins Reich der Phantasie und der absichtsvollen Übertreibung verwiesen. Mit einem einzigen Federstrich werden ganze Bibliotheken getilgt und von einer aufklärerischen Kritik aus dem Reich von Wahrheit oder zumindest Wahrscheinlichkeit ausgebürgert. Was bleibt dann noch übrig von der zivilisatorischen Leistung der indigenen Bevölkerung des Kontinents, von der Baukunst, dem Staatswesen, den Handelsverflechtungen, den kulturellen Errungenschaften der indigenen Hochkulturen? Die Antwort auf diese Frage ist denkbar einfach und mechanisch; sie lässt jene Dialektik der Aufklärung erkennen, auf die wir schon so häufig stießen:

Ohne die Wissenschaft der Mechanik \& die Erfindung ihrer Maschinen gäbe es keine großen Monumente. Ohne Viertelkreise \& ohne Teleskop keinen wunderbaren Fortschritt in der Astronomie, keine Genauigkeit in den Beobachtungen. Ohne Eisen keine Hämmer, keine Zangen, keine Einfassungen, keine Schmieden, keine Sägen, keine Äxte, keine Holzfällerbeile, keinerlei Werke aus Metall, die es verdienten, angeschaut zu werden, nichts an Mauerwerk, nichts an Fachwerk, nichts an Zimmermannskunst, nichts an Architektur, an Gravur, an Skulptur. [...]

Entkleiden wir daher Mexiko all jener Dinge, welche fabelhafte Erzählungen ihm zuschrieben, \& so werden wir herausfinden, dass dieses Land, das den wilden Gebieten

103 Raynal, Guillaume-Thomas: Histoire des deux Indes, Bd. 3, S. 223: „Leur race n’est plus. Il faut que je m'arrête ici un moment. Mes yeux se remplissent de larmes, \& je ne vois plus ce que j'écris.“

104 Vgl. Ette, Ottmar: Diderot et Raynal: l'œil, l’oreille et le lieu de l'écriture dans l'„Histoire des deux Indes“. In: Lüsebrink, Hans-Jürgen / Strugnell, Anthony (Hg.): L'“Histoire des deux Indes,,: réécriture et polygraphie. Oxford: Voltaire Foundation 1996, S. 385-407. 
weit überlegen war, welche die Spanier bis dahin in der Neuen Welt durchstreift, nichts war im Vergleich mit den zivilisierten Völkern des alten Kontinents. ${ }^{105}$

Diese Passage aus der Feder Denis Diderots ${ }^{106}$ zeigt mit aller wünschenswerten Deutlichkeit, wie eine (in diesem Falle materialistisch fundierte) eurozentrische Sichtweise nicht nur die eigene Kultur beziehungsweise Kulturgeschichte und insbesondere deren Techniken zum Maß aller Dinge macht. Vielmehr negiert sie auch die ,andere“ „Kultur“ als solche und charakterisiert sie nur durch den Mangel, durch das Fehlen bestimmter aus europäischer Sicht für essentiell gehaltener Elemente. Das ,Andere‘ wird im Namen des ,Eigenen', das zum ,Universalen“ wird, getilgt und aus der Geschichte der Menschheit mit kritisch-aufklärerischer Geste ausgeschlossen. Man könnte auch formulieren: Im Namen des ,Universalen“ wird das ,Andere‘ schlicht durch das Licht der Aufklärung ausgeblendet.

Diese Passage zeigt zugleich, dass damit alles, was vor der Eroberung durch die Europäer lag, aus der Kulturgeschichte Amerikas ausgebürgert wird. Damit wird Platz geschaffen für eine Entwicklung, die die spanische Eroberung und Kolonialzeit zwar kritisiert sowie verurteilt, zugleich aber die Begründung dafür liefert, dass die künftige Entwicklung dieser außereuropäischen Regionen für universalgültig gehaltenen europäisch-okzidentalen Prinzipien folgen muss. Aufklärung kann eben auch Verdunkelung sein: Die Dialektik der Aufklärung erweist sich auch im transarealen Zusammenhang.

Im Kontext unserer Überlegungen geht es mir dabei weniger um die offenkundige Bewegung einer eurozentrischen und logozentrischen Kolonialisierung, die sich - wie so häufig und bis in unsere Tage - im Gewand der Modernisierung präsentiert. Sie tut dies so, als ginge es nur darum, diese Gesellschaften in Übersee stärker zu modernisieren, um sie von aller Rückständigkeit zu befreien und den europäischen Gesellschaften gleich zu machen. Von gewiss nicht geringerer Bedeutung ist die Tatsache, dass damit ein kultureller Raum geschaffen wird, der als Grundlage für den künftigen politischen, wirtschaftlichen und gesellschaftlichen Bewegungsraum von einer grundlegenden Homogenität geprägt ist, die freilich stets bemüht sein muss, ,störende‘ Elemente auszublenden. Die neue soll in die Fußstapfen der alten Welt treten, doch kann sie ihrer Bewegung ständig beschleunigter Modernisierung nur dann unterworfen werden, wenn aus europäischer Sicht fremdkulturelle Praktiken in einem stets erneuerten Ritual verdrängt werden. Dies ist gerade in einer Phase beschleunigter Globalisierung der Fall, die stets auch eine Phase beschleunigter Modernisierung ist.

105 Raynal, Guillaume-Thomas: Histoire des deux Indes, Bd. 3, S. 248 f.

106 Vgl. hierzu die grundlegende Arbeit von Duchet, Michèle: Diderot et l'Histoire des deux Indes. L'Ecriture Fragmentaire. Paris: Nizet 1978, S. 73. 
Dies betrifft alle Kulturtechniken: Mit derselben Geste, mit der auf die mexikanischen Bilderhandschriften hingewiesen wird, werden diese Piktogramme aus dem Bereich der alphabetischen Schrift ausgegrenzt. Jahrhunderte noch seien die Mexikaner von der „écriture“, „ce moyen puissant \& peut-être unique de lumière“ aufgrund der „imperfection de ces hiéroglyphes“107 entfernt gewesen. Alphabetschrift und Aufklärung sind ein Bündnis eingegangen, das nun aus europäischer Sicht universalisiert wird. Nur der von Europa beschrittene Weg, nur die von Europa gewählte Schriftweise ist die allein richtige und erfolgversprechende Lösung für alle Probleme und kulturellen ,Rückständigkeiten'. Nur mit Hilfe derartiger Mechanismen kann ein kulturell homogener Raum erzeugt werden, der als Grundlage für importierte Modernisierungsprozesse taugt. Die in der Histoire des deux Indes mehrfach geäußerte Kritik an den „kastilischen Geschichtsschreibern“ verdeckt freilich nur für die nicht näher mit den amerikanischen Verhältnissen vertrauten Leser, dass diese ,aufgeklärte‘ Kritik das Verschweigen, die Nicht-Beschäftigung mit anderen, mit indigenen beziehungsweise aus dem Lande selbst stammenden Quellen notdürftig kaschiert. Eine simple Konfrontation mit Francisco Javier Clavijeros Historia antigua de México zeigt die ganze Gefährlichkeit dieser europäischen Aufklärungskritik auf.

Es kann an dieser Stelle unserer Vorlesung nicht darum gehen, jene bereits aus verschiedenen Perspektiven beleuchtete Geschichte der Auseinandersetzung um die Neue Welt noch weiter aufzurollen. Sie verschärfte sich ausgehend von den Schriften Montesquieus und Buffons und der von ihnen abgeleiteten Klima- und Kulturtheorie im letzten Drittel des 18. Jahrhunderts deutlich und führte zu verbitterten Kontroversen um die These vom Degenerieren aller Lebens- und Kulturformen in der sogenannten Neuen. Es scheint mir aber noch nicht ausreichend untersucht worden zu sein, welche Auswirkungen und Nebeneffekte die in dieser Polemik von amerikanischer Seite oft als Gegenprojekte präsentierten Entwürfe in Hinblick auf die Ausgestaltung (eigener) kultureller Räume in Amerika hatten und haben. Dabei hatten wir bereits gesehen, dass Clavijero in seiner Historia antigua de México einen plurikulturellen Raum ersonnen hatte, der im Grunde wesentlich zukunftsträchtiger war als jene Visionen künftiger Homogenität nach europäischem Vorbild. Wir stoßen hier gewiss nicht zum letzten Mal im Verlauf unserer Vorlesung an die Grenzen Europas und eines universalisierenden europäischen Denkens. Wir sollten dabei nicht vergessen, dass wir die Erben dieser Aufklärung sind. Allein die Tatsache, dass die außereuropäische Aufklärung nur bestenfalls sporadisch an den europäi-

107 Raynal, Guillaume-Thomas: Histoire des deux Indes, Bd. 3, S. 254. 
schen Forschungszentren untersucht wird, sollte uns vor Augen führen, dass es an dieser wichtigen Stelle transarealer Beziehungen in Europa ein großes Problem dabei gibt, die eigene Geschichte kritisch aufzuarbeiten und zu reflektieren. Die dringliche Notwendigkeit eines neuen Verständnisses der Aufklärungsepoche scheint mir evident.

Wir haben gesehen, dass sich Europa in dieser zweiten Phase beschleunigter Globalisierung sehr intensiv mit Außereuropa auseinandersetzte und auch in der außereuropäischen Welt eine sehr spezifische Reaktion und Appropriation des europäischen Denkens sich bemerkbar machte. Dies erfolgte ebenso auf der Ebene der intellektuellen, philosophischen, literarischen und kulturellen wie politischen Entwürfe als auch auf jener der konkreten Realisierung bis hin zur Unabhängigkeitsrevolution in den hispanoamerikanischen Kolonien. Wir haben daher auch gesehen, dass die europäische Aufklärung sehr wohl diese außereuropäische Welt wahrnahm, ihre Probleme behandelte und die Ergebnisse dieser Auseinandersetzung an zentraler Stelle in das Denken der europäischen Aufklärung Eingang fanden. Die Frage Außereuropas ist also keine Marginalie innerhalb der Aufklärung, sondern ein sehr wesentlicher Bestandteil eines Denkens, auf das wir uns heute noch immer beziehen. Die Problematik dieses Denkens, unserer eigenen Denktraditionen also, muss uns heute vor Augen stehen.

Wichtig ist diese Tatsache nicht nur für eine veränderte Sichtweise der Aufklärung zwischen zwei Welten, sondern auch für die Einsicht in die Tatsache, dass wir zunächst die Lehren aus der Aufklärung des 18. Jahrhunderts - also aus der zweiten Phase beschleunigter Globalisierung - zu ziehen haben werden. Erst danach erkennen wir wirklich unsere eigene Geschichte und damit auch alle Denkmöglichkeiten nach der zurückliegenden vierten Phase beschleunigter Globalisierung. Wir sind noch immer weit davon entfernt, einen neuen Begriff des Verhältnisses zwischen Europa und Außereuropa und der Entwicklung gleichrangiger Beziehungen auf unserem Planeten entwickelt zu haben. Wenn ich die intellektuellen Entwicklungen mit Optimismus betrachte, dann scheint mir, dass wir uns in der historisch einmaligen Situation einer möglichen Öffnung des europäischen Denkens befinden. Dafür ein Bewusstsein zu schaffen, ist ein Ziel dieser Vorlesung. Verzeihen sie mir daher bitte ein gewisses Insistieren auf diesem Aspekt!

Wir kehren noch ein allerletztes Mal zu Raynals Geschichte beider Indien und zu deren Rezeption zurück. Nach der Wende zum 19. Jahrhundert neigte sich die große Zeit erhitzter Debatten wie abgeklärter Auseinandersetzungen um die Neue Welt nicht nur für das auf schroffen Antinomien aufgebaute Werk von Cornelius de Pauw, sondern auch für die Histoire des deux Indes von Guillaume-Thomas Raynal einer Phase der Abkühlung und schließlich ihrem Ende 
zu. Für lange Zeit, wohl bis ins letzte Drittel des 20. Jahrhunderts, war Raynal nur noch einigen wenigen Spezialisten bekannt, waren hinter den epistemologischen Umbrüchen des ausgehenden 18. wie des 19. Jahrhunderts auch seine Schriften hinter dem Horizont der Zeitgenossen verschwunden. Einer der großen Bestseller des Aufklärungszeitalters hatte seinen Glanz bei der Leserschaft eingebüßt.

Einer der profiliertesten Kritiker des Holländers war Drouin de Bercy, der von sich selbst behauptete, als französischer „colon“ in Saint-Domingue tätig gewesen zu sein, als Offizier an der letztlich gescheiterten Expedition der französischen Armee unter General Leclerc während des Feldzuges gegen die Haitianische Revolution teilgenommen und insgesamt dreizehn Jahre in Amerika verbracht zu haben. Es ist bedeutungsvoll, dass er in seinem 1818 in zwei Bänden zu Paris erschienenen Buch L'Europe et l'Amérique comparées Cornelius de Pauw vierzig Jahre nach dem erstmaligen Erscheinen der Recherches philosophiques sur les Américains angriff. Er tat dies, indem er Alexander von Humboldt gegen ihn in Stellung brachte: „His chief method of refuting De Pauw is to confront him with statements from Alexander von Humboldt, whom he quotes as absolute authority. “108 Der epistemologische Bruch, welcher de Pauws und Raynals Werke zum Verschwinden brachte, erhielt so einen wissenschaftsgeschichtlich präzisen Namen - und dies gleichsam am Ende der Auseinandersetzungen zwischen den so unterschiedlichen Kontrahenten in der Berliner Debatte um die Neue Welt.

In der Tat befand sich der jüngere der beiden Humboldt-Brüder, der sich seit der Rückkehr von seiner großen, zwischen 1799 und 1804 gemeinsam mit Aimé Bonpland durchgeführten Amerikareise für lange Jahre in Paris niedergelassen hatte, zu diesem Zeitpunkt längst im Besitz der Diskurshoheit über die amerikanische Hemisphäre. Ein neuer Diskurs über die Neue Welt war entstanden - und erneut spielten dabei Berlin und Potsdam im Verlauf der ersten Hälfte des 19. Jahrhunderts eine wichtige Rolle. Doch auf Alexander von Humboldt werde ich zu einem späteren Zeitpunkt zurückkommen ...

Es ist kurios, den Aufstieg des Abbé Raynal aus der Anonymität zum ,eigentlichen“ Verfasser und Autor der großen Kolonialenzyklopädie zu verfolgen, für die ihm Denis Diderot in mit der Erweiterung seiner Ausgaben zunehmendem Maße die spektakulärsten und beim Publikum wirkungsvollsten Passagen lieferte. Die erste, 1770 erschienene Ausgabe der Histoire des deux Indes besaß noch keinerlei Illustrationen. Sie wurde wahrscheinlich in Holland gedruckt und gab eine falsche Adresse in Amsterdam an, verschwieg aber wohlweislich

108 Church, Henry Ward: Corneille De Pauw, S. 204. 
den Namen ihres Verfassers. Warum trug man Sorge dafür, die Spuren dieses anonymen Verfassers zu verwischen?

Nun, die Erklärung dafür ist leicht zu geben. Denn angesichts des subversiven Charakters zahlreicher Passagen in den sechs Bänden dieser ersten Ausgabe konnte dies nicht überraschen. Viele Zeitgenossen verstanden (sich auf) dieses Versteckspiel aufklärerischer Autorschaft sehr gut. 1774 meldete die Korrespondenz von La Harpe bezüglich dieses anonym erschienen Werkes, „noch kecker als dessen Niederschrift wäre es wohl, diese zuzugeben“. ${ }^{109}$ Seit 1772 war die Geschichte beider Indien in der Tat zum Gegenstand erster staatlicher Zwangsmaßnahmen und Verbote geworden, deren mehrfache Wiederholung gleichsam offiziell den subversiven Charakter dieser Bände über die europäische Kolonialexpansion bestätigte und auf diese Weise dessen Bekanntheitsgrad, Prestige und Wirkung beim französischen Publikum beträchtlich verstärkte. Der Verfasser dieser Bände musste um seine Sicherheit fürchten.

Für die regelmäßigen Besucher Pariser Salons und die Leser der damaligen „Presse manuscrite“, also der literarischen Korrespondenzen oder der sogenannten „Nouvelles à la main“110 - und damit für das gebildete Publikum -, war die Anonymität freilich eher relativer Natur. Raynal war weit davon entfernt, etwas gegen die Gerüchte zu unternehmen, er sei der Verfasser des inkriminierten Werkes. In gewöhnlich wohlinformierten Kreisen glaubte man also zu wissen, wer der wirkliche Verfasser der Histoire des deux Indes war. Vor dem Hintergrund eines steigenden Bekanntheitsgrades, der durch die offiziellen Verbote noch werbewirksam verstärkt wurde, überrascht es nicht, allenthalben in der Presse Nachrichten über den eigentlichen Verfasser der Geschichte beider Indien und überdies seit 1772 im Journal littéraire de Berlin nachdrückliche Hinweise zu finden, die das Werk einem gewissen „M. l'Abbé $\mathrm{R}^{\star \star \star “ ~ z u r e c h n e t e n . ~}$ Die Berliner Kreise waren zu diesem Zeitpunkt längst thematisch sensibilisiert, griff dieses Werk doch direkt in die Berliner Debatte um die Neue Welt ein. Für die Eingeweihten hätte die Anspielung in einem „von der Preußischen Akademie kontrollierten“111 Periodikum kaum deutlicher ausfallen können, war Raynal doch bereits seit 1750 offizielles Mitglied der Berliner Akademie.

So begann ein literarisches Spiel, dessen ästhetische und poetologische Implikationen neue Ausblicke auf ein faszinierendes und facettenreiches Werk er-

109 Zitiert nach Bancarel, Gilles: L’Histoire des deux Indes. Un best-seller du Siècle des Lumières. Impressions du Sud 25 (printemps 1990), S. 55.

110 Vgl. Guénot, Hervé: La réception de l'„Histoire des deux Indes“ dans la presse d'expression française (1772-1781), S. 67-84.

111 Ebda., S. 72. 
öffnen. Es macht auch deutlich, dass wir uns bei Raynal noch mitten in der Berliner Debatte befinden. Die zweite Ausgabe der Histoire des deux Indes erschien 1774 in Den Haag und enthielt erstmals eine Reihe von Stichen. ${ }^{112}$ Das Frontispiz dieser sechsbändigen Oktavausgabe verdient unsere besondere Aufmerksamkeit, zeigt es uns doch auf wunderbare Weise, auf welch hohem Niveau sich derartige Versteckspiele in den internationalen Zirkeln der République des Lettres des 18. Jahrhunderts vollzogen.

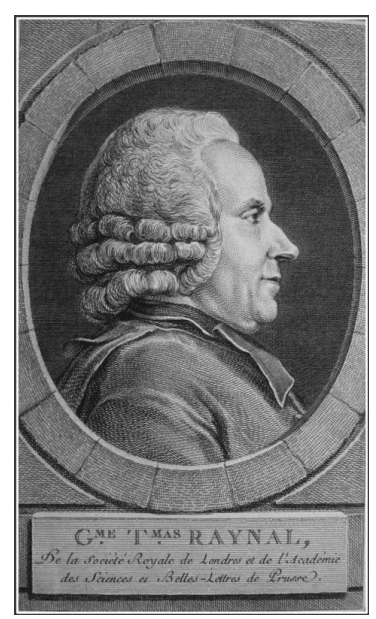

Abb. 35: Porträt von Guillaume Thomas Francois Raynal in der 1774 erschienenen Ausgabe der Histoire des deux Indes.

Gab die Titelseite dieser Ausgabe auch noch immer den Autornamen nicht preis, so bediente das Titelkupfer doch die Neugier des Lesepublikums. Das medaillonförmig geschnittene rechte Profil Raynals wurde durch eine Legende ergänzt, die den Namen von „G. ${ }^{\text {me }}$ T. ${ }^{\text {mas }}$ RAYNAL“ sowie seine Zugehörigkeit zur „Société Royale de Londres et de l'Académie / des Sciences et Belles-Lettres de Prusse“ präzisierte. Damit verwies sie just auf jene Institution, deren Journal littéraire recht unmissverständlich auf die Autorschaft des aus einem kleinen Örtchen in der Nähe des südfranzösischen Rodez stammenden Philosophen hingewiesen hatte. Enthält diese Legende auch keinen Hinweis auf seinen Status als Geistlicher, so lässt die Kleidersprache des Portraits doch keine Zweifel daran aufkommen. Raynals Portrait „en costume ecclésiastique“ zeigt uns „ein von Gutherzigkeit geprägtes beschwichti-

112 Aus einer anderen Perspektive hat Lise Andries auf die Wichtigkeit der Illustrationen der Geschichte beider Indien aufmerksam gemacht; vgl. Andries, Lise: Les illustrations dans l',Histoire des deux Indes“. In: Lüsebrink, Hans-Jürgen / Strugnell, Anthony (Hg.): L',Histoire des deux Indes“: réécriture et polygraphie. Oxford: Voltaire Foundation 1995, S. 11-41. 
gendes Gesicht“113 eines (ebenso offenkundig wie ostentativ) von guten Absichten beseelten Geistlichen. Man denke dabei an die Topoi von der verfolgten Unschuld, wie sie Raynal auch in einem vorhergehenden Zitat selbst verwendet hatte.

Die (wohlgemerkt relative) Anonymität wird durch dieses Frontispiz gelüftet, ohne dass der Autorname auf die Titelseite rückte. Noch erschien er nicht in gedruckter Form. Dies ist der Auftakt zu einem komplizierten Spiel zwischen den verschiedenen schrifttextlichen und nicht-schrifttextlichen Teilen des Paratextes und der semiotischen Strukturierung der Histoire des deux Indes. Dieses schloss einen kreativen Umgang mit den ikonologischen Gepflogenheiten der Zeit mit ein: Nicht von ungefähr zählte der für diesen zeichnerischen Entwurf gewählte Künstler zu den berühmtesten und gesuchtesten Künstlern der Epoche. Denn der auf dem Frontispiz vermerkte Name Charles-Nicolas Cochin war, zusammen mit dem ebenfalls festgehaltenen Namen des Graveurs, sehr wohl in der Lage, die Wichtigkeit der dargestellten Persönlichkeit zu unterstreichen. Gemäß der Konventionen eines Frontispizes, von denen ${ }^{114}$ hier nur die identifikatorische Beziehung zwischen dem Bild der dargestellten Person und den Inhalten der jeweiligen Bildlegende (in diesem Fall unter Angabe der akademischen Titel) erwähnt sei, vermittelte ein so gestaltetes Eingangstor dem gesamten nachfolgenden Werk eine wesentlich höhere Authentizität und Legitimität. Die Bild-Text-Beziehungen bestätigen jenen Prozess einer Autorisierung, in deren Verlauf Guillaume-Thomas Raynal zum ,wirklichen' Autor seiner Histoire des deux Indes wurde.

Dieses erste, in seiner Entstehung auf das Jahr 1773 zurückgehende Frontispiz führte im Gefolge der zweiten Ausgabe zu einer Reihe von Varianten, die auf der Zeichnung Cochins beruhten und unseren Autor bisweilen im rechten, bisweilen im linken Profil zeigten. Der Blick des so Porträtierten richtet sich nach rechts, auf die Titelseite, oder nach links, aber niemals auf die Leserin oder den Leser. Dies verändert sich erst mit der dritten Ausgabe der Histoire des deux Indes, die in Genf 1780 in einer vierbändigen, luxuriös ausgestatteten Quartausgabe erschien. Hier stoßen wir schließlich auf den Autor in seinem Arbeitszimmer, mit der Schreibfeder in der Hand - und mit dem Namen des Autors auf der Titelseite.

Ich möchte an dieser Stelle nicht mehr auf die Bedeutung der Arbeit am Schreibtisch und in einem geschlossenen Raum eingehen - eine Frage von

113 Bancarel, Gilles: G. Thomas Raynal. De la séduction à la sévérité. In: Revue du Rouergue (Rodez) 28 (hiver 1991), S. 480.

114 Die Trennung zwischen Dessinateur und Graveur war im Verlauf des 18. Jahrhunderts immer häufiger geworden; vgl. Wagner, Peter: Lust \& Liebe im Rokoko. Lust \& Love in the Rococo Period. Nördlingen: Delphi 1986, S. 12. In ganz Europa zählten die französischen Künstler im Siècle des Lumières zu den gesuchtesten Buchillustratoren. 
hoher epistemischer Bedeutung, die ich an anderer Stelle erläutert habe. ${ }^{115}$ Mir geht es am Ende dieses Kapitels nur mehr um die Problematik der Autorschaft der Histoire des deux Indes. Denn in Wirklichkeit war Guillaume-Thomas Raynal mehr der kluge und versierte Koordinator der von ihm orchestrierten Texte als deren hauptsächlicher Verfasser. Die Forschungen der letzten Jahrzehnte haben ergeben, welche Vielzahl an Autoren an diesem Gemeinschaftswerk mitarbeitete. Aber sie zeigten auch, welch wichtige Rolle darin Denis Diderot zukam. ${ }^{116}$

Auch wenn wir bei Francisco Javier Clavijero sahen, dass der neuspanische Aufklärer nicht viel Federlesens mit seinen europäischen Kontrahenten machte und einen de Pauw oder Robertson wie einen Raynal behandelte und abtat, so dürfen wir doch in der Geschichte beider Indien den eigentlichen Höhepunkt einer europäischen Epistemologie erkennen. Für sie war der von Jean-Jacques Rousseau so vehement reklamierte „philosophe voyageur“ keine Option, sondern eher ein Schrecknis. Denn wie de Pauw und so viele andere europäische Philosophen war auch Raynal niemals außerhalb Europas gewesen. Er stand daher in den Debatten klar für einen überlegenen europäischen Standpunkt, welcher die Kritik der transatlantischen Aufklärung im Grunde nicht wahrnahm - zu sehr war man in Europa daran gewöhnt, dass die außereuropäischen Gebiete Objekte, aber nicht Subjekte der Forschung und öffentlichen Meinungsbildung waren.

Raynals Bild des über unserem Planeten schwebenden Philosophen, dessen Position für den Anspruch des Universalismus stand, der über alles auf diesem Globus abschließend zu urteilen befähigt sei, steht für eine Position, die noch immer ein schweres Erbe der europäischen Aufklärung für unsere Zeit ist. Denn die Problematik eines derartigen Universalismus europäischer Prägung ist noch längst nicht vorüber: Ihre Präsenz ist allzu oft mit Händen zu greifen. So mag denn das Gesicht des europäischen Philosophen, das wir im Verlauf der verschiedenen Ausgaben der Histoire des deux Indes haben aufleuchten sehen und das im Übrigen in der zuletzt genannten Kombination mit dem Autornamen nicht mehr die Züge Raynals trug, wieder verschwinden sehen - um Michel Foucault zu zitieren: wie am Meeresufer ein Gesicht im Sand. Die markanten Gesichtszüge einer solchen Epistemologie sind freilich selbst in der europäischen Aufklärungsforschung unserer Tage noch nicht verschwunden, das diffuse Fortwirken der Berliner Debatte ist noch immer nicht zu einem Ende gekommen.

115 Vgl. hierzu Ette, Ottmar: La mise en scène de la table de travail: poétologie et épistémologie immanentes chez Guillaume-Thomas Raynal et Alexander von Humboldt. In: Wagner, Peter (Hg.): Icons - Texts - Iconotexts. Essays on Ekphrasis and Intermediality. Berlin - New York: Walter de Gruyter 1996, S. 175-209.

116 Vgl. das Diderot-Kapitel in Ette, Ottmar: ReiseSchreiben S. 169-185. 